\title{
Modeling the long-term diffusion and feeding capability of a
} mega-nourishment

\author{
Jaime Arriaga ${ }^{\mathrm{a}, *}$, Jantien Rutten $^{\mathrm{b}}$, Francesca Ribas ${ }^{\mathrm{a}}$, Albert Falqués ${ }^{\mathrm{a}}$, Gerben Ruessink ${ }^{\mathrm{b}}$ \\ ${ }^{a}$ Universitat Politècnica de Catalunya, Department of Physics, Jordi Girona 1-3, 08034, Barcelona, Spain \\ ${ }^{b}$ Utrecht University, Faculty of Geosciences, Department of Physical Geography, Heidelberglaan 2, 3584 CS, Utrecht, \\ Netherlands
}

\section{Abstract}

A morphodynamic model based on the wave-driven alongshore sediment transport, including crossshore transport in a simplified way and neglecting tides, is presented and applied to the Zandmotor meganourishment on the Dutch Delfland coast. The model is calibrated with the bathymetric data surveyed from January 2012 to March 2013 using measured offshore wave forcing. The calibrated model reproduces accurately the surveyed evolution of the shoreline and depth contours until March 2015. According to the long-term modeling using different wave climate scenarios based on historical data, for the next 30-yr period, the Zandmotor will display diffusive behavior, asymmetric feeding to the adjacent beaches, and slow migration to the NE. Specifically, the Zandmotor amplitude will have decayed from $960 \mathrm{~m}$ to about $350 \mathrm{~m}$ with a scatter of only about $40 \mathrm{~m}$ associated to climate variability. The modeled coastline diffusivity during the 3-yr period is $0.0021 \mathrm{~m}^{2} / \mathrm{s}$, close to the observed value of $0.0022 \mathrm{~m}^{2} / \mathrm{s}$. In contrast, the coefficient of the classical one-line diffusion equation is $0.0052 \mathrm{~m}^{2} / \mathrm{s}$. Thus, the lifetime prediction, here defined as the time needed to reduce the initial amplitude by a factor 5 , would be $90 \mathrm{yr}$ instead of the classical diffusivity prediction of $35 \mathrm{yr}$. The resulting asymmetric feeding to adjacent beaches produces $100 \mathrm{~m}$ seaward shift at the NE section and $80 \mathrm{~m}$ seaward shift at the SW section. Looking at the variability associated to the different wave climates, the migration rate and the slight shape asymmetry correlate with the wave power asymmetry ( $\mathrm{W}$ vs $\mathrm{N}$ waves) while the coastline diffusivity correlates with the proportion of high-angle waves, suggesting that the Dutch coast is near the high-angle wave instability threshold.

Keywords: Sand Engine, morphodynamic modeling, shoreline diffusivity, high-angle wave instability, mega-nourishment, alongshore transport

\section{Introduction}

Protecting beaches from erosion is an important issue in the context of climate change and the increasing need for sustainable coastal development. Nourishments are common soft protection measures (Hamm et al., 2002), their magnitude and periodicity varying in different countries. Spain, Italy and France have an interest in coastal development projects (e.g., harbors) and apply a strategy of remediation when negative impacts induced by these projects require coastal stabilization (Hamm et al., 2002). In the Netherlands, coastal protection is a high-level priority as reflected in its coastal policy of maintaining the coastline position at its 1990 position (de Ruig and Hillen, 1997). As a consequence, innovative large-scale solutions have been implemented such as the construction of a mega-nourishment, called Sand Engine (Zandmotor in Dutch, from now on referred to as ZM), in July 2011 (Stive et al., 2013). The ZM is expected to diffuse mainly

\footnotetext{
*Corresponding author

Email addresses: jaime.alonso.arriaga@upc.edu (Jaime Arriaga), J.Rutten@uu.nl (Jantien Rutten), francesca.ribas@upc.edu (Francesca Ribas), albert.falques@upc.edu (Albert Falqués), B.G.Ruessink@uu.nl (Gerben Ruessink)
} 
due to the alongshore transport, which acts as the main distributor of sand along the adjacent coast, and to feed a large beach stretch instead of local erosional hot spots only. The ZM consists of $17 \mathrm{Mm}^{3}$ of sand and affects depth contours until $8 \mathrm{~m}$ depth, driving the local profiles far away from their previous state (de Schipper et al., 2016). Therefore, cross-shore diffusion is also expected. According to Stive et al. (2013) and de Schipper et al. (2014), the envisioned lifetime of the ZM is of the order of 15-20 yr.

The large length and time scales involved in the evolution of the ZM are challenging and it is not obvious to decide on the appropriate modeling strategy (de Schipper et al., 2014). For short time scales, full 2D models, which take into account many processes, can perform rather well. However, for long-term modeling their computational cost is too high. In contrast, one-line models are more simplistic (e.g., they ignore surf-zone dynamics) and computationally cheap, offering a plausible alternative for long-term modeling. In general, bathymetric perturbations influence the wave field through wave transformation and wave focusing, leading to gradients in the alongshore transport that may develop erosional hot spots (Bender and Dean, 2003; van den Berg et al., 2011). These gradients can be forced by offshore features (template forcing) but also can occur by a positive feedback from the evolving shoaling zone morphology into the wave field. This feedback has been largely ignored by traditional one-line models and this is why they always predict diffusive behavior. If the feedback is considered, the coastline diffusivity is reduced (Falqués, 2003). For lowangle and long-period waves the feedback is negligible but it can be strong for high-angle and short-period waves (Falqués and Calvete, 2005). In the latter case, the diffusivity can even become negative resulting in an unstable coastline (Ashton et al., 2001) and hence into the formation of alongshore rhythmic shoreline undulations that influence the bathymetric contours well beyond the surf zone, called shoreline sand waves (SSW). This mechanism is known as HAWI (High-Angle Wave Instability). At the Dutch coast, Ruessink and Jeuken (2002) analyzed data of dunefoot position dating back to as early as 1850, detecting the presence of small amplitude SSW and discussed the HAWI mechanism as a possible explanation. Falqués (2006) made an analysis of the Dutch coast with a shoreline instability model, finding that with the present wave climate the shoreline was stable but that slightly increasing the percentage of obliquely incident waves the coast could become unstable. Even if the coastline is stable, its evolution can still be affected by the HAWI mechanism as it can cause a decrease in diffusivity and an alongshore migration of shoreline perturbations (van den Berg et al., 2011).

The cross-shore dynamics in the models of Ashton et al. (2001) and Falqués (2006) was highly idealized, overpredicting the potential for shoreline instability (van den Berg et al., 2012). The Q2D-morfo model (van den Berg et al., 2012) is also based on the wave driven alongshore transport but the cross-shore dynamics is incorporated by reproducing the tendency of the profiles to relax to a prescribed equilibrium profile. Wave propagation over the evolving bathymetry is solved but the internal morphodynamics of the surf zone (bars and rips) is ignored. In spite of the higher complexity, the Q2D-morfo model can still handle large temporal and spatial scales. So far, the Q2D-morfo model has mainly been used to understand the physical mechanisms driving the formation of SSW with an alongshore spacing in the range of 1-10 km. It was first applied to explore the potential triggering of SSW by nourishments (van den Berg et al., 2011). Later on, $80 \%$ of oblique waves (i.e., larger than $42^{\circ}$ at the depth of closure) was found to be the limit necessary for the instability to develop (van den Berg et al., 2012). More recently, the physical mechanisms for the SSW wavelength selection were unraveled (van den Berg et al., 2014). However, the validation of model results with observations was made in a rather qualitative way, running idealized configurations (e.g., using idealized profiles and perturbations, synthetic or even constant wave conditions, etc.) and contrasting against nature by looking only at the SSW wavelengths (Falqués et al., 2011b), partially due to scarcity of data at these large temporal $(\sim \mathrm{yr})$ and spatial $(\sim \mathrm{km})$ scales (especially regarding bathymetric data).

The two primary objectives of the present paper are (i) to calibrate and validate the Q2D-morfo model, for which the large scales of the ZM and its intense monitoring offer a unique opportunity, and (ii) to assess, using the validated Q2D-morfo model and historic-measured-wave data, the long-term behavior of the ZM, including its diffusion, migration, feeding capability to adjacent beaches and its potential to trigger SSW. An improved version of the Q2D-morfo model is described in Section 2. Due to the large shoreline angles induced by the mega-nourishment, a new algorithm is implemented to define the shoreline and the 'crossshore transport' is defined in the direction of the maximum local bed slope. The study site and available data are described in Section 3. The first step of this study is to quantitatively calibrate and validate the 
improved version of the model using the available surveyed data of the ZM evolution (Section 4). The results of the modeled long-term behavior of the mega-nourishment during $30 \mathrm{yr}$ are described in Section 5. Section 6 contains a discussion of the results and Section 7 lists the conclusions of the study.

\section{Q2D-morfo model}

\subsection{General description}

The Q2D-morfo model is a nonlinear morphodynamic model for large scale shoreline dynamics. As explained before, it is based on the wave driven alongshore sediment transport, but it incorporates the cross-shore transport in a heuristic manner. Tide and wind forcings are not accounted for and the surf zone internal dynamics are filtered out. The model uses a Cartesian frame of reference, where the y-axis is parallel to the mean shoreline and the x-axis is pointing offshore (Fig. 1), and a rectangular domain $\left(0<x<L_{x}, 0<y<L_{y}\right), L_{x}$ and $L_{y}$ being the cross-shore and the alongshore domain lengths, with $x$ cell grid size, $\Delta x$, and $y$ cell grid size, $\Delta y$.

The initial model version, described in detail in van den Berg et al. (2012), had two important shortcomings that limited its applicability to the ZM conditions. First, the evolving shoreline was treated as a sharp boundary between the dry and wet beach, which was difficult to implement numerically. In particular, the model could not discretize correctly the shoreline evolution when the shoreline deviated more than some $13^{\circ}$ from the $\mathrm{y}$-axis, which is an angle considerably lower than the initial ZM largest shoreline angle. Here, we present an improved version of the model where the shoreline is not treated as a boundary by implementing the fuzzy shoreline algorithm: the dynamic equations are now solved throughout the whole domain and the shoreline is treated as a transition zone (more details can be found in Section 2.3). This allows the description of larger shoreline deviations. Second, the cross-shore transport was assumed to follow the global x-axis, which is valid if the shoreline and the associated bathymetric contours display only small amplitude undulations. However, the ZM is a large amplitude perturbation. Therefore, in the improved model version the cross-shore direction is computed locally as the direction of maximum bed level gradient (i.e., the normal direction to the local contours) of a smoothed bathymetry.

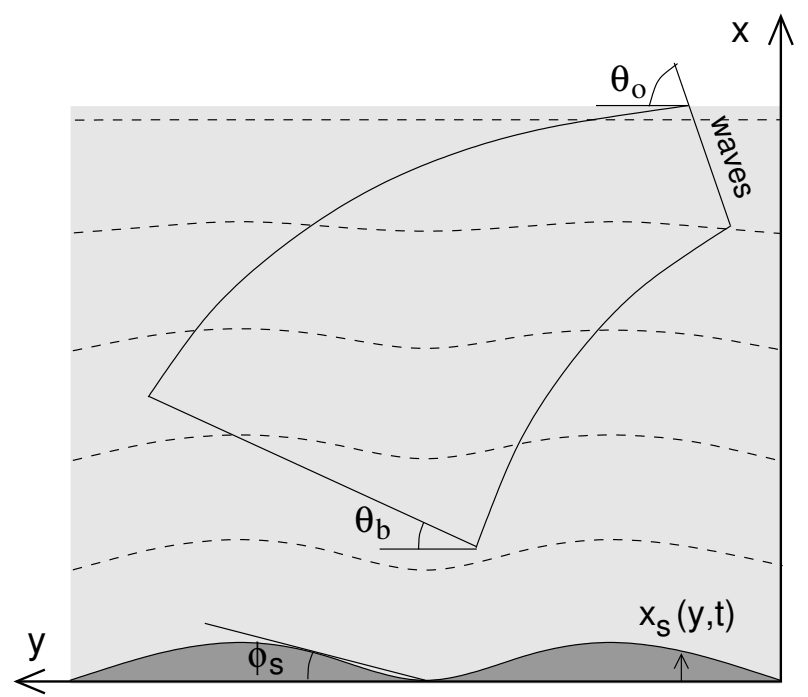

Figure 1: Sketch of the nearshore region in plan view with the coordinate system.

\subsection{Wave transformation}

The wave module takes into account refraction and shoaling over the curvilinear contours by assuming monochromatic waves with $T=T_{p}$ (peak period), $H=H_{r m s}$ (root-mean-square wave height) and a wave 
angle $\theta$. The waves are propagated from the offshore boundary $\left(H_{0}, T_{0}, \theta_{0}\right)$ by solving in cascade a set of three decoupled equations: the dispersion relation, the equation for wave number irrotationality and the wave energy conservation equation:

$$
\begin{gathered}
w^{2}=g k \tanh (k D) \\
\frac{\partial k_{y}}{\partial x}=\frac{\partial k_{x}}{\partial y}
\end{gathered}
$$

$$
\frac{\partial}{\partial x}\left(c_{g} H^{2} \frac{k_{x}}{k}\right)+\frac{\partial}{\partial y}\left(c_{g} H^{2} \frac{k_{y}}{k}\right)=0
$$

Here, $\omega$ is the radian frequency, $g$ is the gravity acceleration, $\vec{k}=\left(k_{x}, k_{y}\right)=k(-\cos \theta, \sin \theta)$ is the wave number vector (where $\theta$ is the angle between wave crests and the $y$-axis, see Fig. 1), $c_{g}$ is the group celerity, and $D$ the local depth. These equations ignore wave diffraction, and wave energy dissipation by bottom shear stress and wave breaking. From the computed wave field, we extract the breaker wave height, $H_{b}$, and the corresponding wave angle, $\theta_{b}$, to feed the sediment transport equation. The breaking point is the most onshore position where $H \leq \gamma_{b} D, \gamma_{b}$ is the saturation ratio of $H / D$ in the surfzone. We take the value $\gamma_{b}=0.5$.

\subsection{Bed evolution}

The changes in the bed level are computed with the sediment mass conservation equation

$$
\frac{\partial z_{b}}{\partial t}+\frac{\partial q_{x}}{\partial x}+\frac{\partial q_{y}}{\partial y}=0
$$

where $\vec{q}=\left(q_{x}, q_{y}\right)$ is the depth-integrated sediment flux, which includes the bed porosity factor, and $z_{b}$ is the bed level. This is the main governing equation and it is solved throughout the whole domain. The shoreline position, $x_{s}(y, t)$ is computed from the modeled $z_{b}$ interpolating between the last wet cell and the first dry cell and is assumed to be a univalued function of $y$, so hook shapes cannot be represented. The first important improvement of the present version of the model is to treat the shoreline as a transition zone (i.e., a fuzzy shoreline, which can be interpreted as the swash zone) where all the variables and functions change smoothly from certain values corresponding to the wet cells to other values corresponding to the dry cells. For example, the wave-driven alongshore transport is assumed to have a standard cross-shore distribution in the surf zone and decays to zero across the swash zone, and the factor in front of the cross-shore transport is assumed to have a certain distribution in the surf and shoaling zones and it is imposed to decay exponentially to zero across the swash zone (the mathematical details are described later on in this Section). This rather simple concept facilitates the numerical implementation of the sediment transport equations and solves the $13^{\circ}$ numerical limitation of the previous version of the model. The second important improvement is to take into account the curvature of the shoreline and its associated bathymetric contours. The local normal direction is represented by an averaged orientation, $\phi$, evaluated as

$$
\sin \phi=\frac{\frac{\partial \bar{z}_{b}}{\partial y}}{\sqrt{\left(\frac{\partial \bar{z}_{b}}{\partial y}\right)^{2}+\left(\frac{\partial \bar{z}_{b}}{\partial x}\right)^{2}}},
$$

where the spatially averaged bed level $\bar{z}_{b}$ is computed within a rectangular box $L_{l} \times L_{c}$. Here, $L_{l}=100 \mathrm{~m}$ and $L_{c}=50 \mathrm{~m}$ are used. For the coastline angle, $\phi_{s}$, the boxes do not take into account the dry cells in order to avoid the influence from the dry beach. Following the model convention, the normal vector is $\hat{n}=(\cos \phi,-\sin \phi)$ and the tangential vector is $\hat{t}=(\sin \phi, \cos \phi)$.

The depth integrated sediment flux $\vec{q}$ is decomposed as

$$
\vec{q}=\overrightarrow{q_{L}}+q_{N}+\overrightarrow{q_{D}}
$$

where the first term, $\overrightarrow{q_{L}}$, represents the littoral drift driven by breaking waves and is evaluated by first computing the total sediment transport rate $Q$. Here, the CERC formula (Komar, 1998) is chosen,

$$
Q\left(y^{\prime}\right)=\mu H_{b}^{5 / 2} \sin \left(2 \alpha_{b}\right)
$$


where $H_{b}$ is the (rms) wave height at breaking and $\alpha_{b}=\theta_{b}-\phi_{s}$ is the angle between wave fronts at breaking and the coastline (Fig. 1). Here, $y^{\prime}$ (instead of $y$ ) indicates that the variables $H_{b}, \theta_{b}$ and $\phi_{s}$ associated to each point correspond to the position found following the direction normal to the local coastline (instead of the global $x$ direction). The $\mu$ constant is related to the non-dimensional $K$ constant of the original CERC formula by

$$
\mu=\frac{K}{16(s-1)(1-p)} \sqrt{\frac{g}{\gamma_{b}}}
$$

where $s$ and $p$ are the relative density and porosity of sediment, respectively. By setting $s=2.65, p=0.4$ and $\gamma_{b}=0.5$, the range $K \sim 0.2-1.6$ suggested by Komar (1998) gives a range $\mu \sim 0.06-0.45 \mathrm{~m}^{1 / 2} \mathrm{~s}^{-1}$. The parameter $\mu$ will be calibrated in Section 4.1. The total $Q$ is then redistributed across the profile with a normalized shape function, which is assumed to be similar to a alongshore current profile:

$$
f\left(x^{\prime}\right)=\frac{4}{\sqrt{\pi} L^{3}} x^{\prime 2} e^{-\left(x^{\prime} / L\right)^{2}}
$$

where $x^{\prime}$ is the distance to the shoreline and $L=0.7 X_{b}^{\prime}+X_{s z}^{\prime}$, with $X_{b}^{\prime}$ being the width of the surfzone and $X_{s z}^{\prime}$ being the width of the swash zone. The cross-shore coordinate $x^{\prime}$, and the distances $X_{b}^{\prime}$ and $X_{s z}^{\prime}$ are calculated in the direction normal to the local coastline by using the corresponding $\phi$ (Eq. 5). The cross-shore distribution of $f\left(x^{\prime}\right)$ in Eq. (9) is based on alongshore current measurements reported by Komar (1998) for a wide range of beach profiles. Finally, we impose that the transport $\overrightarrow{q_{L}}$ is directed tangent to the local bathymetric lines,

$$
\overrightarrow{q_{L}}=Q\left(y^{\prime}\right) f\left(x^{\prime}\right) \hat{t}
$$

The second term in Eq. $(6), \overrightarrow{q_{N}}$, stands for the transport that drives the bathymetry to a certain crossshore equilibrium profile, i.e., it parameterizes the cross-shore transport processes, and reads

$$
\overrightarrow{q_{N}}=-\gamma_{N}\left(\nabla z_{b} \cdot \hat{n}+\beta_{e}\right) \hat{n}
$$

and is proportional to the difference between the equilibrium slope $\beta_{e}$, at the local depth $D=-z_{b}$, and the actual slope in the local shore-normal direction. An implicit assumption of this approach is that the equilibrium profile must be monotonic (without bars). The cross-shore diffusivity factor $\gamma_{N}$ is related to the influence of orbital velocities and turbulence produced by incoming waves on the sea bed. Its order of magnitude has been estimated from the expression of momentum mixing (Battjes, 1975) and it is scaled with a power of wave height at breaking,

$$
\gamma_{N}=\nu \gamma_{b}^{-1 / 6} H_{b}^{11 / 6} X_{b}^{-1 / 3} \psi
$$

where $\nu$ is a non-dimensional parameter that will be calibrated in Section 4.1. The factor $\gamma_{N}$ varies throughout the bathymetry with a shape function $\psi$, which has a maximum at the shoreline and then decays offshore (imitating the cross-shore distribution of wave orbital motion) and onshore (Fig. 2). In the wet cells the expression

$$
\psi\left(z_{b}\right)=\frac{1+b+\tanh \left(\left(\alpha D_{c}+z_{b}\right) / L_{d}\right)}{1+b+\tanh \left(\alpha D_{c} / L_{d}\right)}
$$

is adopted, which becomes 1 at the shoreline and decays to a given value $f$ (here, $f=0.02$ and is controlled by the parameter $b$ ) at $D=D_{c}$. The model instantaneous depth of closure, $D_{c}$, is computed as a fraction of the depth at which the sediment particles are first mobilized by the waves, $D_{m}\left(D_{c}=f_{c} D_{m}\right.$, where the parameter $f_{c}$ is calibrated in Section 4.1). The residual value of $\psi$ at deep water is controlled by the parameter $\alpha$. Here, $\alpha=0.46$ so that $\psi(\infty) \sim f / 2=0.01$. The decay rate of $\psi$ is controlled by $L_{d}$, here set to $L_{d}=0.5 \alpha D_{c}$. In the dry cells, $\psi(x)$ decays to 0 in the onshore direction as

$$
\psi(x)=\exp \left(-\left(\frac{x-x_{s}}{X_{s z}}\right)^{4}\right)
$$




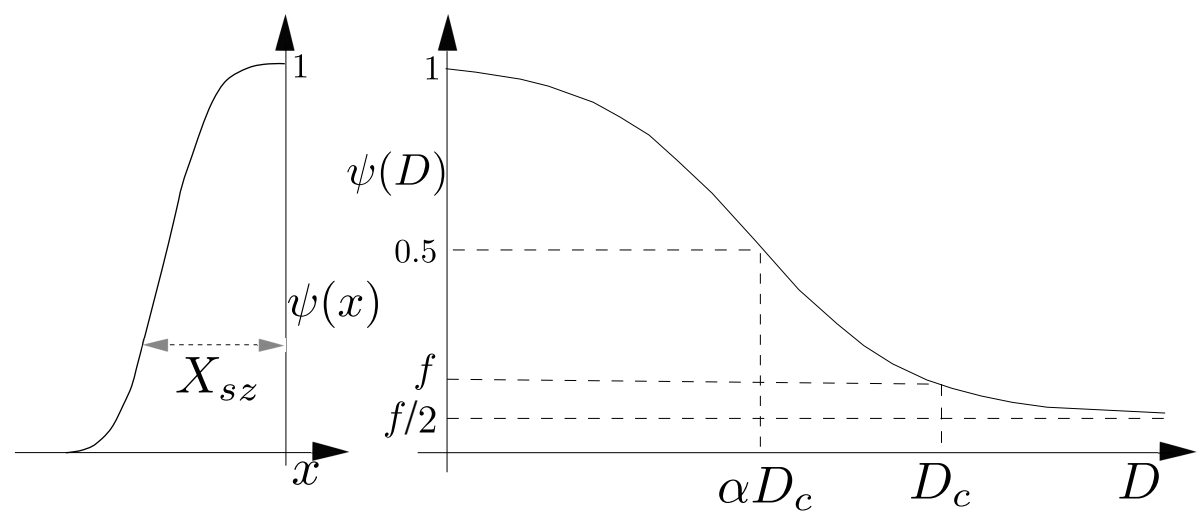

Figure 2: Sketch of the $\psi$ function (Eqs. 13 and 14), which controls the cross-shore transport magnitude and imitates the cross-shore distribution of wave orbital motion. A large residual value $f$ has been used to allow visualization.

where $x-x_{s}$ is the distance to the shoreline and the width of the swash zone $X_{s z}$ controls the decay distance.

The third term in Eq. (6), $\overrightarrow{q D}$, represents the tendency of small bumps to be flattened by breaking waves and it helps to stabilize the numerical solution by diffusing the small-scale morphodynamic noise.

$$
\overrightarrow{q_{D}}=-\gamma_{D}\left(\nabla z_{b} \cdot \hat{t}\right) \hat{t}
$$

The alongshore diffusivity factor $\gamma_{D}$ is of the same order of the cross-shore factor $\gamma_{N}$ (Eq. 12) and follows the same shape function $\psi$ (Eqs. 13 and 14).

\subsection{Numerical implementation and boundary conditions}

The bed evolution Eq. (4) is discretized using an explicit second order Adam-Bashforth scheme in time and a standard finite differences method in space. The values applied here for the grid size and the time step (of morphological evolution) are: $\Delta x=6 \mathrm{~m}, \Delta y=50 \mathrm{~m}$ and $\Delta t=0.001 \mathrm{~d}$. A ratio $\Delta x / \Delta y<0.25$ for $\theta_{0}<89^{\circ}$ is required to prevent that the waves exit the grid cell trough a lateral boundary (van den Berg et al., 2012). Due to the slow changes in the bed level it is not necessary to compute the wave field at every time step. We found that updating the wave field each $\Delta t_{w}=0.1 \mathrm{~d}$ (i.e., every 100 steps of bed evolution) does not affect the morphological evolution even in extreme conditions such as storms.

Offshore and lateral boundaries are open, i.e., the sediment in the domain is not necessarily constant. At the offshore boundary $\left(x=L_{x}\right)$ we impose a linear extrapolation of the inner bathymetry. At the lateral boundaries $\left(y=0, L_{y}\right)$, the profile relaxes to the equilibrium profile, following the position of the global shoreline, with an exponential decay given by the decay distance $\lambda$,

$$
\frac{\partial\left(z_{b}-z_{b e}\right)}{\partial y}= \pm \lambda^{-1}\left(z_{b}-z_{b e}\right)
$$

where $z_{b e}$ is the bed level of the equilibrium profile. Once the bathymetry outside the boundaries is imposed, the alongshore, normal, and diffusive transports are computed as in any other point. The condition imposed at the onshore boundary $(x=0)$ is that the cross-shore sediment transport equals $0\left(q_{x}=0\right)$.

\section{Site description}

The ZM is a hook-shaped mega-nourishment of $17 \mathrm{M} \mathrm{m}^{3}$, with an initial alongshore length of $2.4 \mathrm{~km}$ and an offshore extension of $1 \mathrm{~km}$, constructed from March 2011 to July 2011 within the $17 \mathrm{~km}$-long beach section (Delfland coast) bounded by the harbors of Scheveningen and Hoek van Holland (Fig. 3a). Furthermore, the design contained a small lake to prevent the freshwater lens in the dunes to migrate seaward. This mega-nourishment project is a coastal protection measure on decadal time scales to maintain the coastline under the predicted sea-level rise (Stive et al., 2013). 
a)

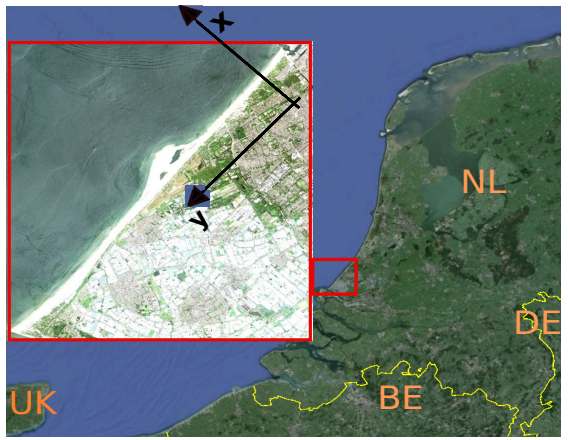

b)

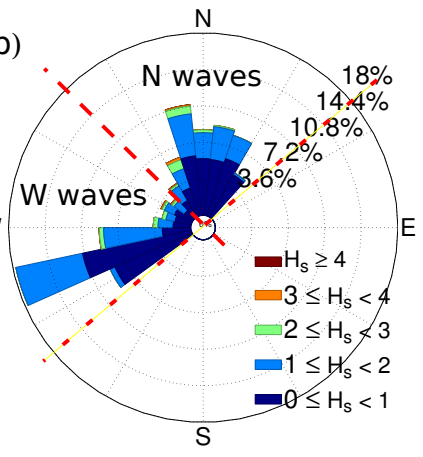

C)

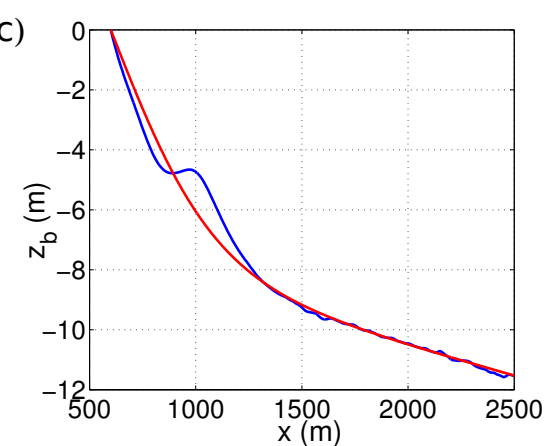

Figure 3: (a) ZM location, with the model coordinate system, (b) directional distribution of $H_{s}$ at the Europlatform buoy (32 $\mathrm{m}$ depth), and (c) time-and-space-averaged bed elevation, $z_{b}$, versus distance $x$ in the ZM area (blue line) and the adjusted profile (red line) of Yu and Slinn (2003). 


\subsection{Waves and tides}

The governing offshore wave climate has a yearly mean wave height $\left(H_{m 0}\right)$ of about $1.3 \mathrm{~m}$ and a yearly mean wave period $\left(T_{m 01}\right)$ of about $5-6 \mathrm{~s}$. There is a clear seasonal variability: from November to January the mean wave height is $1.7 \mathrm{~m}$ and from April to August it is about $1 \mathrm{~m}$ (Wijnberg and Terwindt, 1995). Waves mainly approach the coast from the southwest and the north-northwest (Wijnberg and Kroon, 2002) (Fig. $3 \mathrm{~b}$ ). For the present study, the significant wave height $\left(H_{s}\right)$ peak period $\left(T_{p}\right)$, and angle $\left(\theta_{0}\right)$ were extracted every $3 \mathrm{~h}$ from the Europlatform buoy located at $32 \mathrm{~m}$ depth ignoring the waves directed seaward (Fig. 3b). The waves are transformed from the buoy to the offshore model boundary using Snell law and energy conservation. Since the offshore wave climate is rather alongshore uniform at the Dutch coast (Wijnberg and Terwindt, 1995) this buoy is representative even though it is not directly in front of the ZM. The tide in the Delfland coast is semi-diurnal with a mean range of $1.7 \mathrm{~m}$ (Wijnberg and Terwindt, 1995).

\subsection{Morphology}

The sediment in this area has a median grain size of $250 \mu \mathrm{m}$ (Wijnberg and Terwindt, 1995) and the median grain size of the ZM is $280 \mu \mathrm{m}$ (de Schipper et al., 2016). The equilibrium profile, required by the model $\left(\beta_{e}\right.$ in Eq. 11 and $z_{b e}$ in Eq. 16), was extracted from the long-term JarKus data set by averaging the profiles spatially and temporally. The JarKus annual profiles usually start in the dune area and end at about $800 \mathrm{~m}$ seaward with $250 \mathrm{~m}$ alongshore spacing. Every $5 \mathrm{yr}$, coastal profiles are surveyed up to about $2500 \mathrm{~m}$ seaward with $1 \mathrm{~km}$ alongshore spacing. The alongshore spatial distance for the derivation of the averaged profile was of $10 \mathrm{~km}$ around the ZM, and the temporal period chosen, which agrees with the change in coastal policy, is from 1990 to 2009 (de Ruig and Hillen, 1997). The equilibrium profile for the model (Fig. 3c) is obtained from the averaged profile by adjusting the profile of Yu and Slinn (2003) without bars

$$
z_{b e}(x)=-a_{1}\left(1-\frac{\beta_{2}}{\beta_{1}}\right) \tanh \left(\frac{\beta_{1} x}{a_{1}}\right)-\beta_{2} x
$$

where $\beta_{1}$ is the slope at the shoreline and $\beta_{2}$ is the slope at depth $a 1$. We also verified the sensitivity of the model to using different equilibrium beach profiles, obtained by averaging over different spatial and temporal ranges (varying from an area of 1 to $10 \mathrm{~km}$ around the ZM and from 5 to $40 \mathrm{yr}$ before the ZM construction), and no appreciable changes were observed.

In the framework of the ZM project, bathymetric surveys were performed every month in the first year after the installation, and every two months in the subsequent years. The bathymetries extend $1.5 \mathrm{~km}$ offshore and $4.5 \mathrm{~km}$ alongshore. The grid resolution is $2 \mathrm{~m}$ and $25 \mathrm{~m}$ in the cross-shore and alongshore coordinates, respectively. The initial bathymetry for the model simulations corresponds to the survey of 17 January 2012 (Fig. 4a), once the initial hook-shape (which cannot be represented by the present model version, as explained in Section 2.3) had connected to the adjacent beach (Fig. 4a), creating a second enclosed water body. The initial model bathymetry is made by combining bathymetric data from the intensively surveyed area of the ZM with the equilibrium profile extracted from the Jarkus data set for the remainder of the modeled domain. In the bathymetries of the ZM area, we filter out the bars using the volume approach (Kaergaard et al., 2012) to meet the model assumption of a monotonic equilibrium profile. First, for each depth the bed level was integrated over a vertical range, the resulting volume was converted to distance from a fixed location on the beach, obtaining a clean profile with the volume conserved and without bars (see dashed line in Fig. 5). Second, the surveyed dry beach area was added, with the inner water bodies treated as $0.1 \mathrm{~m}$ high dry beach. Third, the contours in the model domain outside of the ZM area were constructed following the equilibrium profile assuming a straight shoreline (i.e., the overall position of the shoreline previous to the ZM construction). Finally, the bathymetry was interpolated from the overlapped contours (Fig. 4b).

\section{Calibration and validation}

\subsection{Model calibration}

The model was initialized with the measured bathymetry from 17 January 2012 (see Section 3.2) and the three most influential parameters were calibrated by comparing the modeled and the measured bathymetries 

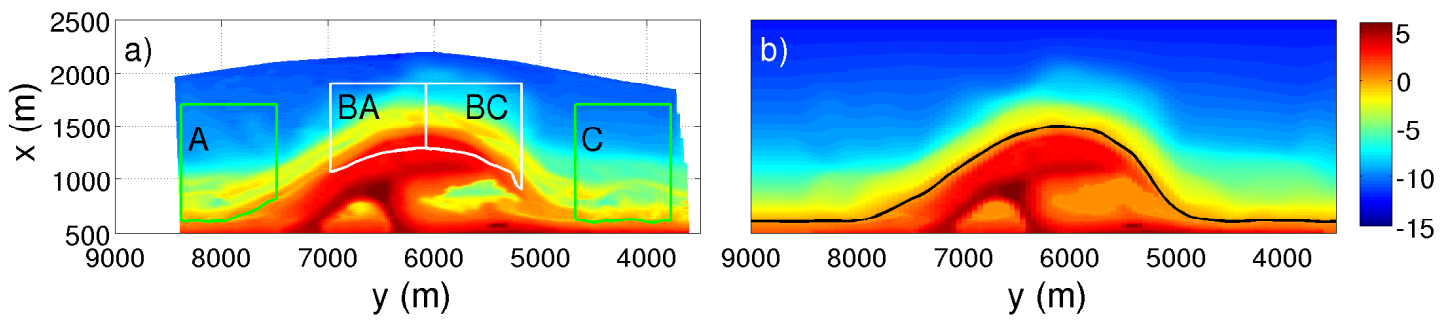

Figure 4: (a) Bathymetric survey from 17 January 2012 with volume control boxes and (b) input bathymetry of the model with the bars filtered out and the lagoons adjusted.

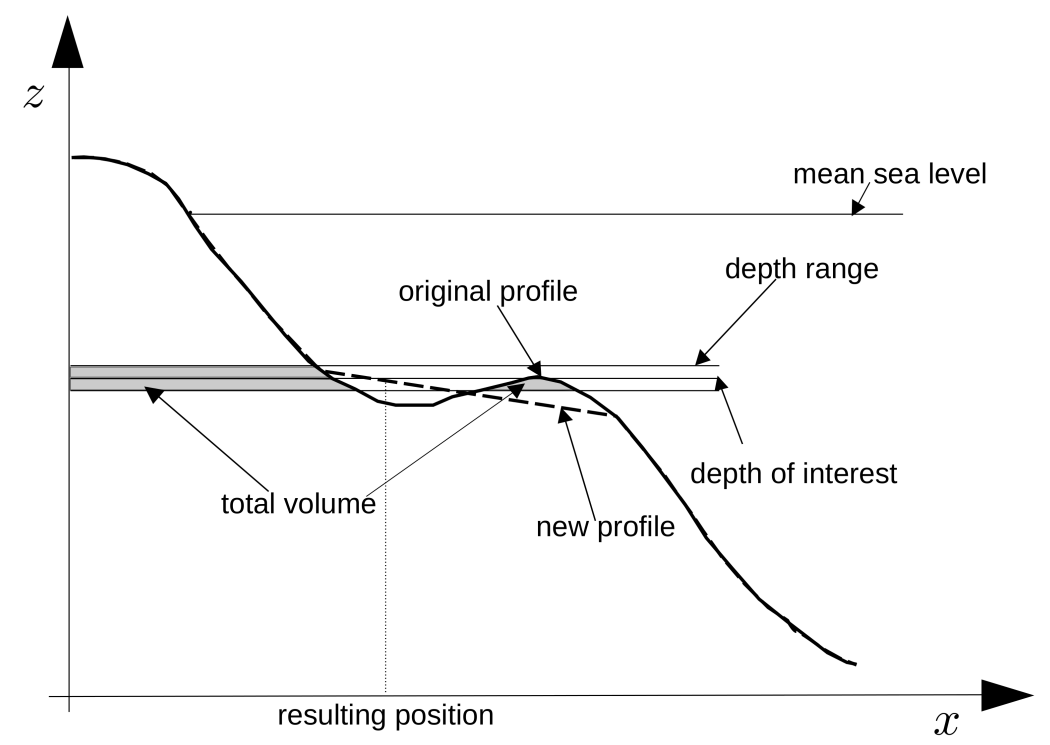

Figure 5: Sketch of the volume approach. Thick solid line corresponds to the original profile. Thick dashed line corresponds to the profile after filtering out the bar with the volume approach.

after about $400 \mathrm{~d}$ (to take into account seasonality), forcing the model with the wave data from the Europlatform buoy. The first parameter, $\mu$, controls the magnitude of the alongshore sediment transport (Eq. 7), the second parameter, $f_{c}$, controls the depth where the cross-shore and diffusive transports (Eqs. 11 and 15) drop to $\sim 0$ (i.e., it controls the active depth for sediment transport), and the third parameter, $\nu$ controls the magnitude of the cross-shore and diffusive transports (i.e., it controls the relaxation time to equilibrium). In this contribution, we have simplified the calibration process by using the same values for $\nu$ and $f_{c}$ for both transports, as in van den Berg et al. (2012). Thereby, $\gamma_{D}=\gamma_{N}$. The range of values used for calibrating these parameters are $\mu=[0.01 ; 0.04 ; 0.07 ; 0.10] \mathrm{m}^{1 / 2} \mathrm{~s}^{-1}, \nu=[0.01 ; 0.03 ; 0.05]$ and $f_{c}=[0.05 ; 0.15 ; 0.25 ; 0.35 ; 0.45]$. Larger $\mu$ values were not included because preliminary model simulations showed that they largely overpredicted the ZM diffusion. The values for $f_{c}$ and $\nu$ were chosen because they are physically meaningful and still prevent numerical instabilities. From observations, it is clear that a factor $f_{c}>0.50$ is not plausible (e.g., using $f_{c}=0.5$, the active depth would be $9.31 \mathrm{~m}$ for $H_{r m s}=1 \mathrm{~m}$ and $T_{p}=6 \mathrm{~s}$ ). On the other hand, if there is important alongshore sediment convergence and not enough capacity to redistribute it cross-shore, "unphysical" islands tend to grow and the simulations blow up. Finally, a very high $\nu$ value is equivalent to an unrealistic instantaneous shift of the profile as in the one-line models. This gives a constraint on the ratio $\mu / \nu$. 
The model performance was evaluated with the root-mean-square skill score, $R M S S S=1-\operatorname{RMSE}(Y, X) / \operatorname{RMSE}(B, X)$, of the modeled contours (until $10 \mathrm{~m}$ depth). In the definition of the RMSSS, RMSE stands for the root-mean-squareerror, $X$ is a set of $n$ measurements, $x_{1}, x_{2}, \ldots, x_{n}, Y$ is a set of corresponding predictions, $y_{1}, y_{2}, \ldots, y_{n}$, and $B$ is the prediction of no change (i.e., the initial survey), also called baseline prediction (Sutherland et al., 2004). The contours of the bathymetric survey were extracted using the volume approach (see Section 3.2). The root-mean-square errors were weighted over the depth contours with a coefficient of $0.9^{D}$ ( $D$ being the water depth) so the coastline and shallow contours have more weight than deeper contours. Perfect agreement (i.e., $\operatorname{RMSE}(Y, X)=0$ ) gives a $R M S S S$ of 1 . If the model prediction is further away from the measured condition than the baseline prediction, the RMSSS becomes negative .

In general, after $400 \mathrm{~d}$ the $R M S S S$ improved with decreasing $f_{c}$ (Fig. 6a). For $f_{c}=0.05$ the simulations became unstable for $\mu \geq 0.04 \mathrm{~m}^{1 / 2} \mathrm{~s}^{-1}$ and low $\nu$ values, which can be explained by a lack of capacity to redistribute the accumulated sediment in the cross-shore direction. The best RMSSS was obtained for $f_{c}=0.15$ and $\mu=0.04 \mathrm{~m}^{1 / 2} \mathrm{~s}^{-1}$. When using these values, the $R M S S S$ was similar for $\nu=0.03$ and $\nu=0.05$. We have chosen the latter to ensure the simulations stability in energetic situations.
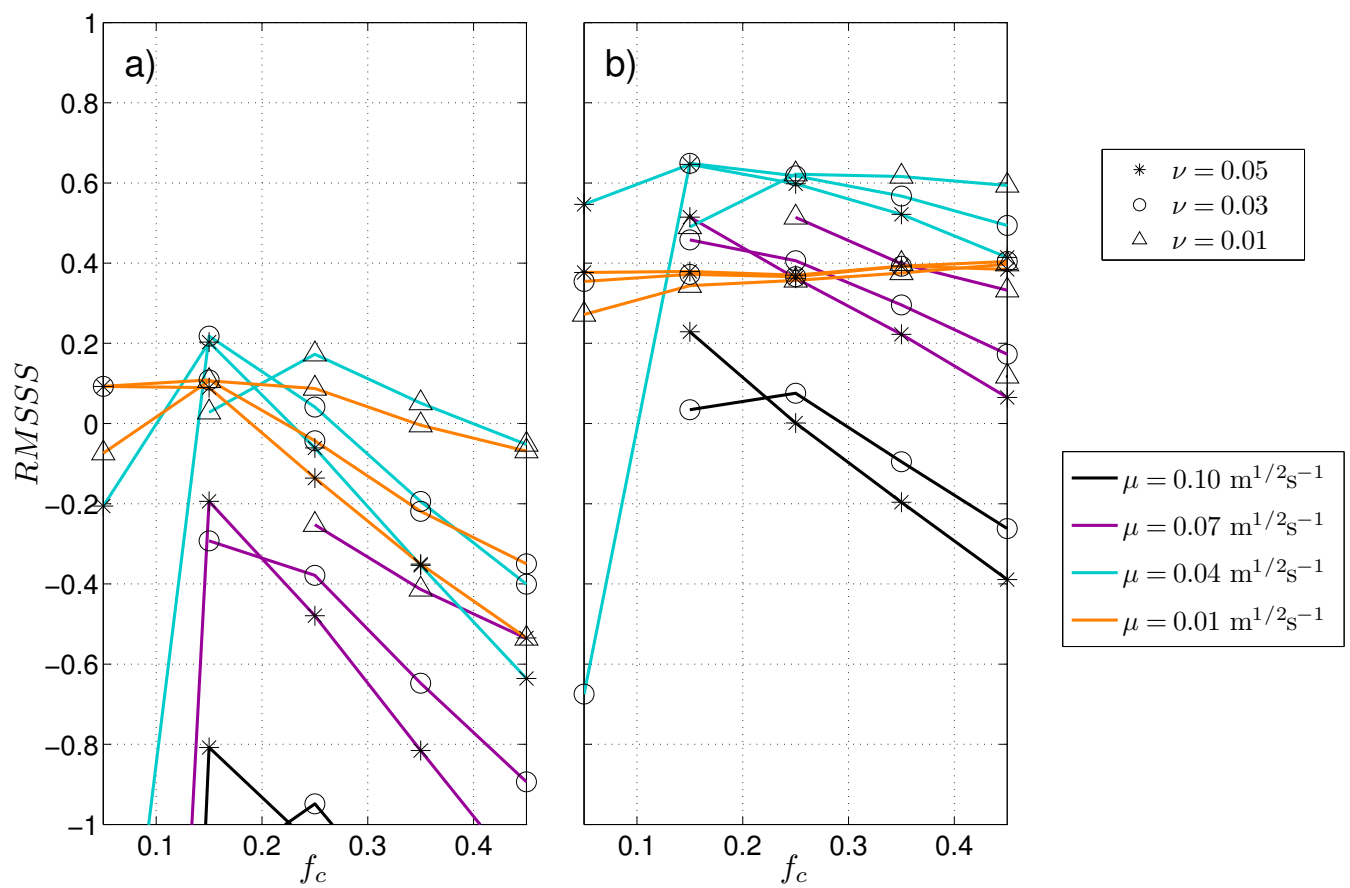

Figure 6: Root-mean-square skill score of the bathymetric lines (a) after $400 \mathrm{~d}$ and (b) after $1150 \mathrm{~d}$, as a function of $f_{c}, \mu$, and $\nu$.

\subsection{Model validation}

To validate the model calibration, we first compute the RMSSS after $1150 \mathrm{~d}$ for the same range of parameter values of the previous section, confirming that the calibrated valueshave the best performance (Fig. 6b). In particular, after $400 \mathrm{~d}, \mu=0.01 \mathrm{~m}^{1 / 2} \mathrm{~s}^{-1}$ and $\mu=0.04 \mathrm{~m}^{1 / 2} \mathrm{~s}^{-1}$ have similar performance but after $1150 \mathrm{~d}$ their performance gap increases and $\mu=0.04 \mathrm{~m}^{1 / 2} \mathrm{~s}^{-1}$ clearly reproduces the observations more accurately. This can be explained by the initially fast cross-shore dynamics in the model (see Section 4.3), adapting rapidly (i.e., faster than in reality) the profile (hence, the contours) to a quasi-equilibrium state. This adaptation initially disguises the role of $\mu$. 


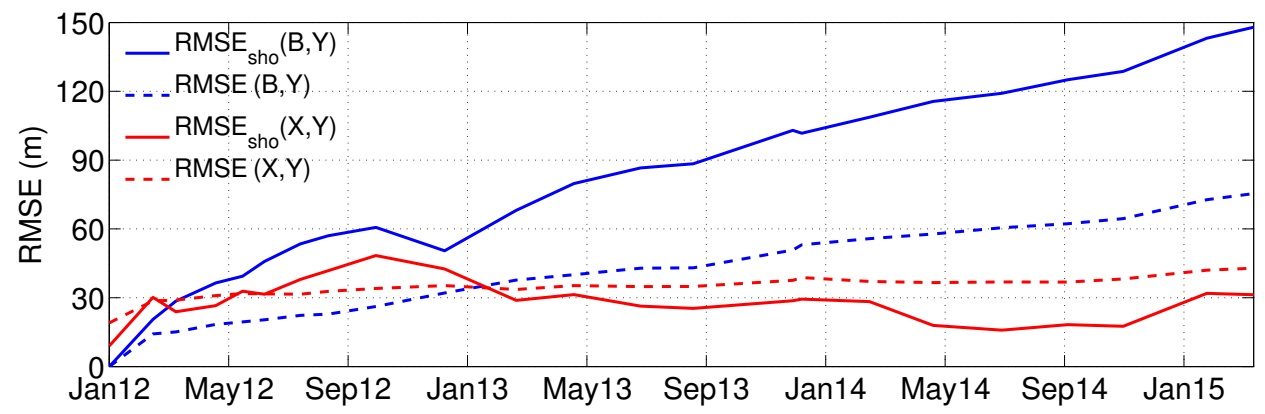

Figure 7: Comparison of $R M S E$ of the no-change prediction (blue lines) and of the calibrated model (red lines). The solid lines correspond to the shoreline and the dashed lines correspond to the bathymetric lines until $10 \mathrm{~m}$ depth.

The RMSSS of the calibrated model after $1150 \mathrm{~d}$ is about a factor 3 larger than after $400 \mathrm{~d}$ (Fig. 6). The skill score of the calibrated model increases continuously in time because $R M S E(B, Y)$ experiences a continuous increase (Fig. 7, blue dashed line) due to the ZM diffusive nature whereas $R M S E(X, Y)$ hardly grows (Fig. 7, red dashed line). In fact, the $R M S S S$ increases for every set of parameter values, so that a sub-optimal set of tuning calibration parameters $\left(\mu, f_{c}, \nu\right)$ may eventually reach high $R M S S S$ values. Therefore, we have to interpret the RMSSS values carefully. The Q2D-morfo is based on the one-line approach and as such it represents better the shoreline than the bathymetric lines. Indeed, the root-mean-square error of the shoreline, $R M S E_{\text {sho }}(X, Y)$, shows an initial increment then a decay and a subsequent stabilization while oscillating around the value $30 \mathrm{~m}$ (Fig. 7, solid red line). The modeled shoreline differs more from the observed one in the north-east side (Fig. 8a) probably because the model does not take into account the interaction between the lagoon and the sea. Also, small scale undulations in the bathymetric lines (related to processes such as surfzone dynamics) are not captured in the simulations which are a persistent source of error in the quantification (Fig. 8b).
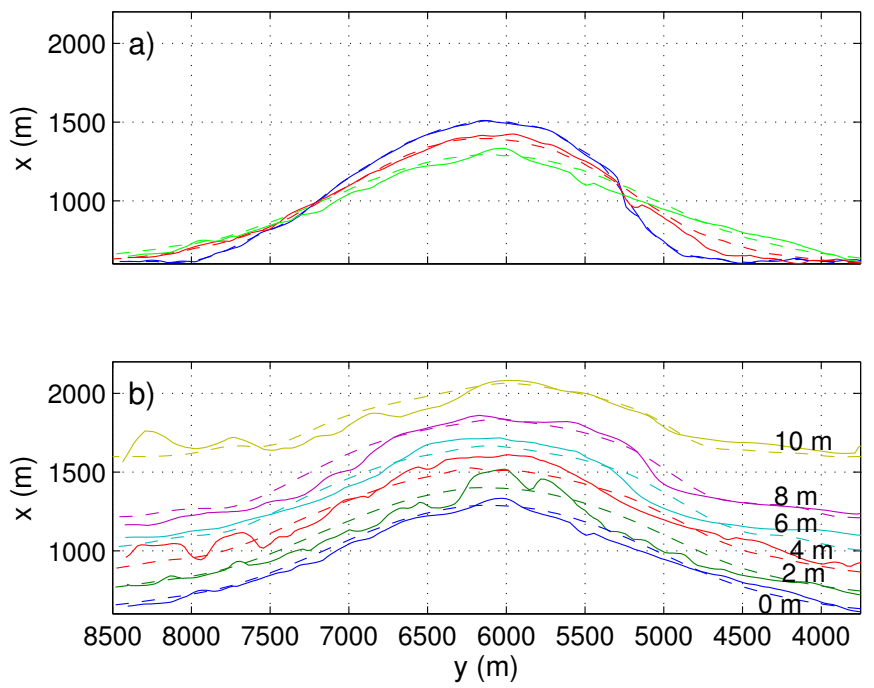

Figure 8: (a) Shoreline position on January 2012 (blue), after 400 d, on March 2013 (red), and after 1150 d, on March 2015 (green). (b) Bathymetric lines every $2 \mathrm{~m}$ until $10 \mathrm{~m}$ depth after $1150 \mathrm{~d}$. Measured (solid line) and modeled (dashed line).

To further validate the model results, we also compared how the volumes of sand changed over $1150 \mathrm{~d}$ in 
three control boxes $(\mathrm{CB})$ representative of the ZM tip (B) and the adjacent beaches (A, to the SW, and $\mathrm{C}$, to the NE, see Fig. 4a). Here, CB-B is expected to loose sand while the CB-A and the CB-C are expected to gain sand. A quantification of the model performance is given with the following averaged volume error

$$
E_{*}=\frac{\sqrt{\frac{1}{N} \sum_{i=1}^{N}\left(V_{*}(i)_{m e s}-V_{*}(i)_{s i m}\right)^{2}}}{\max \left(V_{* m e s}\right)-\min \left(V_{* m e s}\right)}
$$

where $V_{*}$ stands for the volume in box ${ }^{*}, i$ for the survey number, $N$ for the number of surveys, sim for simulations and mes for measurements. Overall, the diffusion of the ZM over the adjacent beaches is well represented by the model (Fig. 9). The modeled loss of sand in the tip (CB-B) resembles the measured one $\left(E_{B}=0.09\right)$. The initial offset in volume isa result of the linear interpolation used in the construction of the modeled bathymetry (the modeled wet area had $0.5 \%$ less sand than the survey). To reveal more detail, CB-B is decomposed into its south-west (Fig. 9BA) and north-east (Fig. 9BC) sides. The CB-BC has a lower error $\left(E_{B C}=0.07\right)$ than that of the CB-BA $\left(E_{B A}=0.17\right)$, and their behavior is consistent with their respective tip sides $\left(E_{C}=0.06\right.$ and $\left.E_{A}=0.19\right)$. The model generally underestimates the volume in CB-A except for the last survey, while for CB-C the differences are small throughout time except for the underfeeding observed in the last survey. In general, the modeled volume change (Fig. 9, right axis) of CB-B, CB-BA and CB-BC follow the measured trend with small magnitude differences while the modeled and measured volume changes of CB-A and CB-C (the ones being fed) show more significant differences. The long-term trend is captured in the global volume behavior.

\subsection{Computation of shoreline diffusivity}

The analytic formulation required to infer the actual diffusivity of the simulations, $\epsilon_{Q 2 D}$, and of the observations, $\epsilon_{o b s}$, is obtained here using the concept of shoreline diffusivity, easily formulated within the framework of the one-line approximation for shoreline dynamics. By assuming a certain alongshore sediment transport simplification/parameterization and neglecting the feedback of bathymetric changes into the wave propagation, the Pelnard-Considère equation is obtained (Pelnard-Considère, 1956)

$$
\frac{\partial x_{s}}{\partial t}=\epsilon \frac{\partial^{2} x_{s}}{\partial y^{2}}
$$

where $\epsilon$ is the diffusivity coefficient assumed constant.

An analytic solution of Eq. (19) is derived by approximating the initial shoreline, $x_{s}(y, 0)$, to a Gaussian shape (e.g., after $1150 \mathrm{~d}$ the surveyed shoreline has a $18.6 \mathrm{~m}$ mean square error with respect to a Gaussian shape) and then expanding it as a Fourier integral, leading to

$$
x_{s}(y, 0)=A_{0} e^{-\left(\left(y-y_{a}\right) / L\right)^{2}}=A_{0} \frac{L}{\sqrt{\pi}} \int_{0}^{\infty} e^{-k^{2} L^{2} / 4} \cos \left(k\left(y-y_{a}\right)\right) d k
$$

where the amplitude is

where $A_{0}$ is the initial amplitude, $L$ is the initial Gaussian width and $y_{a}$ is the alongshore location of the crest. Using the boundary conditions: $x_{s}(-\infty, t)=x_{s}(\infty, t)=0$, and performing some computations, the analytic solution of Eq. (19) can be cast into:

$$
x_{s}(y, t)=A(t) \exp \left(-\frac{\left(y-y_{a}\right)^{2}}{L^{2}+4 \epsilon t}\right)
$$

$$
A(t)=\frac{A_{0}}{\sqrt{1+4 \epsilon t / L^{2}}}
$$

The classical diffusivity coefficient, $\epsilon_{c l a}$, using the CERC formula for the alongshore transport simplification, is

$$
\epsilon=\epsilon_{c l a}=2 \mu \frac{H_{b}^{5 / 2}}{D_{c}} \cos \left(2 \theta_{b}\right),
$$



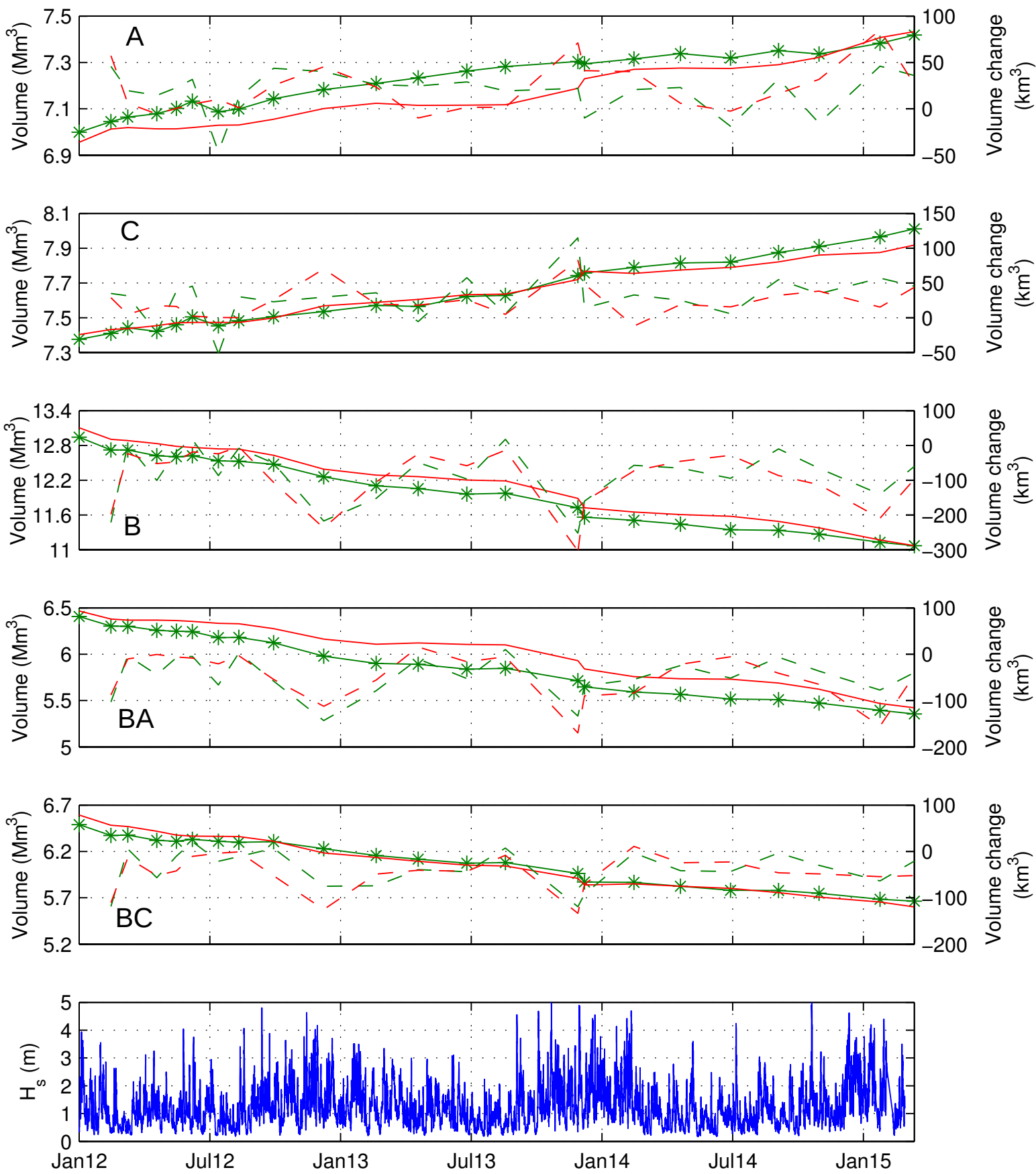

Figure 9: Modeled (red) and measurements (green) total volume (solid lines) and volume change (dashed lines) in the control windows defined in Fig. 4a. The asterisks indicate the surveyed data points. The significant wave height is plotted in the lower panel. 
to evaluate $\epsilon_{c l a}$ we assume a constant $D_{c}$ of $8 \mathrm{~m}$, inferred from the measured contours and consistent with the analysis of de Schipper et al. (2016). To compute the instantaneous $H_{b}$ and $\theta_{b}$ in Eq. (23), waves are propagated from the buoy until the breaking point with the Snell law and the energy conservation, assuming parallel contours to a straight shoreline. Then, we average the resulting instantaneous diffusivity coefficient over the three years of evolution, giving $\epsilon_{c l a}=0.0052 \mathrm{~m}^{2} / \mathrm{s}$.

By using Eq. (22), time dependent values of the modeled and observed diffusivity, $\epsilon_{Q 2 D}$ and $\epsilon_{o b s}$ respectively, can be inferred from the corresponding $A(t)$. The initial amplitude, $A_{0}$, and width, $L$, are obtained by fitting the Gaussian function to the initial shoreline, $x_{s}(y, 0)$, and the subsequent amplitudes, $A(t)$, to the instantaneous shoreline, $x_{s}(y, t)$. Notice that $\epsilon_{Q 2 D}$ and $\epsilon_{o b s}$ represent the effective diffusivity between the initial state and time $t . \epsilon_{o b s}$ decreases in time and stabilizes after $\sim 200 \mathrm{~d}$ (April 2013) to $0.0022 \mathrm{~m}^{2} / \mathrm{s}$ (Fig. 10a). Until this moment the diffusion may not only be driven by alongshore transport (the assumption behind Eq. 19) but also by cross-shore transport, since the perturbed profile is far from the characteristic local equilibrium profile. Similarly, $\epsilon_{Q 2 D}$ stabilizes to $0.0021 \mathrm{~m}^{2} / \mathrm{s}$ but the model overpredicts the initial cross-shore transport contribution (Fig. 10a). During the first days the modeled amplitude decays by $40 \mathrm{~m}$ (Fig. 10b), suggesting a misrepresentation of the cross-shore transport when the initial profiles are far from the defined equilibrium profile. However, the time evolution of the modeled effectivediffusivity presents a change in slope around $200 \mathrm{~d}$ (Fig. 10a), which agrees with the stabilization time of the measurements, and after $500 \mathrm{~d}$ the model catches up with the measurements. A lower $\nu$ value could reduce the cross-shore transport overprediction but numerical instabilities may arise during energetic events.
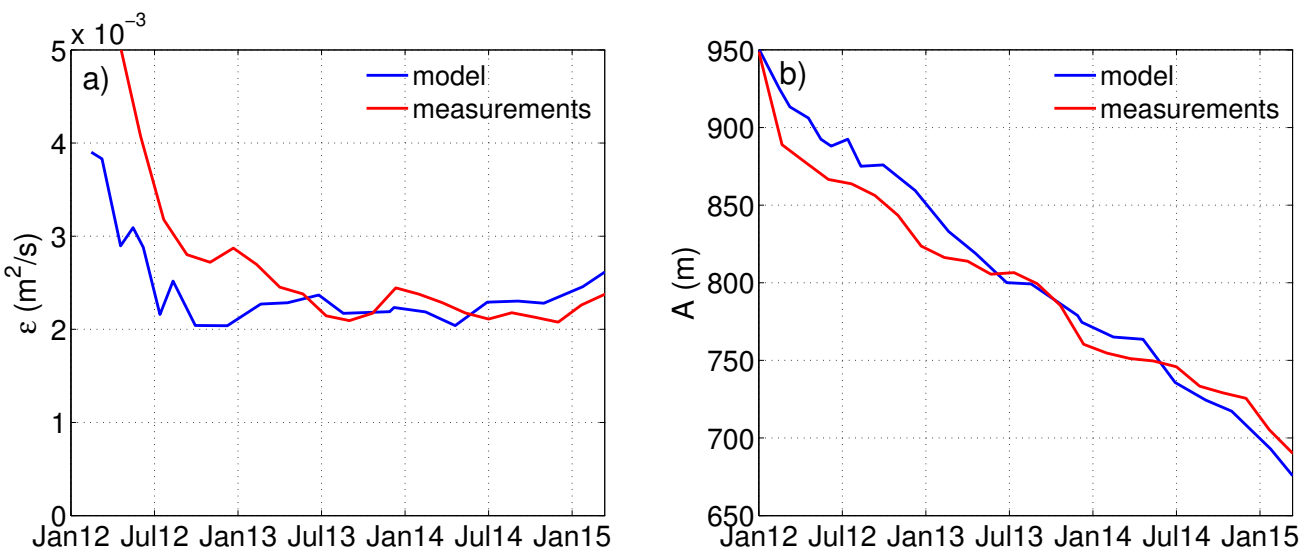

Figure 10: (a) The diffusivity coefficients and (b) the amplitudes, based on the measurements (blue line) and the Q2D-morfo simulations (red line), versus time.

\section{Long-term evolution and feeding capability}

\subsection{Wave climate scenarios}

For the long-term analysis, a total simulation time of $30 \mathrm{yr}$ has been chosen ,which is safely longer than the envisaged time of 15-20 yr (de Schipper et al., 2014; Stive et al., 2013). Considering the validation time of $3 \mathrm{yr}$, the long-term modeling is performed over $27 \mathrm{yr}$. To account for variability in the future wave climate (hereafter referred to as WC), five different WC scenarios have been designed based on the available wave data prior to the last validated simulation (01 March 2015). First, a time interval of $m$ yr is defined and then is repeated until reaching the $27 \mathrm{yr}$ duration. The chosen intervals are $m=1,3,5,10,20 \mathrm{yr}$, so that when $m=1$ the interval is from March 2014 to March 2015 and repeats itself 27 times, for $m=3$ the interval is from March 2012 to March 2015 and repeats itself 9 times, etc.

The WC characteristics, evaluated at the buoy depth of $32 \mathrm{~m}$, are analyzed by first separating the waves coming from the west i.e., $\theta_{0}<0^{\circ}$ with respect to the global shoreline orientation (hereafter referred to as 
Table 1: Statistics of the modeled wave climate scenarios, where $H$ is computed in $H_{s}$ terms and $T$ in $T_{p}$ terms

\begin{tabular}{|l|l|l|l|l|l|l|l|l|l|l|}
$\mathrm{WC}$ & $\mathrm{m}$ & $\bar{H}_{W}(m)$ & $\bar{H}_{N}(m)$ & $\bar{T}_{W}(s)$ & $\bar{T}_{N}(s)$ & $\bar{\theta}_{W}$ & $\bar{\theta}_{N}$ & $P_{T} 10^{8}(W / m)$ & $P_{W} / P_{N}$ & $\% \theta_{\text {oblique }}$ \\
\hline 1 & 1 & 1.48 & 1.00 & 5.87 & 5.90 & 60.2 & 45.2 & 1.93 & 2.71 & 61.6 \\
2 & 3 & 1.42 & 1.06 & 5.77 & 5.94 & 61.7 & 45.9 & 1.92 & 2.02 & 61.9 \\
3 & 5 & 1.41 & 1.10 & 5.76 & 6.00 & 61.4 & 45.3 & 2.01 & 1.80 & 60.9 \\
4 & 10 & 1.40 & 1.13 & 5.78 & 6.00 & 60.1 & 44.9 & 2.02 & 1.66 & 59.4 \\
5 & 20 & 1.39 & 1.13 & 5.82 & 6.01 & 59.8 & 44.2 & 1.90 & 1.62 & 58.0
\end{tabular}

$\mathrm{W}$ waves) from the waves coming from the north i.e., $\theta_{0}>0^{\circ}$ with respect to the global shoreline orientation (hereafter referred to as $\mathrm{N}$ waves). Then, the averaged $H, T$ and $\theta$ are computed for $\mathrm{W}$ and $\mathrm{N}$ waves. Also, the alongshore component of the wave energy flux is calculated as

$$
P=\frac{1}{8} \rho g H^{2} C_{g} \sin \theta
$$

where $\rho$ is the water density. The accumulated module of $P$ is computed as $P_{T}=\sum(|P|)$, and the wave power asymmetry is evaluated as the ratio $P_{W} / P_{N}$. Finally, the percentage of oblique waves (angle larger than $\left.\left|45^{\circ}\right|\right), \% \theta_{\text {oblique }}$, is computed.

The average conditions of the five $\mathrm{WC}$ are similar (Table 1). In general, the $\mathrm{W}$ waves are more oblique and more energetic than the $\mathrm{N}$ waves. The dominant $\mathrm{W}$ wave energy flux is consistent with the known net alongshore sediment transport direction from SW to NE (van Rijn, 1997). The maximum $\bar{H}$ difference among the five different $\mathrm{WC}$ is $0.134 \mathrm{~m}$ (for the $\mathrm{W}$ waves), while for $\bar{T}$ is $0.11 \mathrm{~s}$ (for the $\mathrm{N}$ waves), and for $\theta$ is $1.72^{\circ}$ (for the $\mathrm{N}$ waves). The resemblance in wave statistics gives small differences in $P_{T}$ but the wave power asymmetry shows a decay with larger $m$ values (e.g., $P_{W}(m=1)=2.71 P_{N}$ and $\left.P_{W}(m=20)=1.62 P_{N}\right)$. A similar tendency is observed in $\% \theta_{\text {oblique }}$, which decreases with increasing $m$, indicating an increment of wave obliquity in recent years.

\subsection{Diffusion and feeding properties}

The long-term simulations performed show that the ZM is expected to exhibit continuous diffusion during more than $30 \mathrm{yr}$ (Figs. 11, 12). Therefore, the wave obliqueness of the WC scenarios is not large enough to trigger the formation of self-organized shoreline-sand waves. The long-term effective diffusivity is inferred by using Eq. (22) and the modeled ZM amplitude, $A(t)$, with $A_{0}$ and $L$ corresponding to the first long-term simulation. After some initial variability (during about $5 \mathrm{yr}$ ), the effective diffusivity stabilizes and the averaged value of the last $5 \mathrm{yr}$ is shown in Table 2. The stabilization of the diffusivity supports the use of the analytic solution for long-term prediction of the amplitude of the ZM. The least diffusive wave climate is $\mathrm{WC} 2$, and the most diffusive is WC5, with a $40 \mathrm{~m}$ difference in amplitude after $27 \mathrm{yr}$.

The one-line approximation using the classic diffusive coefficient, $\epsilon_{c l a}$, computed in Section 4.3, predicts a significantly larger decay. As shown in Fig. 12, after 10 yr the amplitude predicted by the classical one-line approach would be $31 \%$ smaller than the one predicted by the Q2D-morfo model. Using $\epsilon_{Q 2 D}=$ $0.0021 \mathrm{~m}^{2} / \mathrm{s}$ (calculated with the first $3 \mathrm{yr}$ evolution), the one-line approach follows reasonably well the amplitude although after the first five years starts to diverge (Fig. 12). The lifetime of the ZM can be defined as the time period required for its amplitude to decrease to a given factor of its amplitude after construction, and here we choose a factor 0.2 . Using $\epsilon_{c l a}=0.0052 \mathrm{~m}^{2} / \mathrm{s}$ the lifetime is $\sim 35 \mathrm{yr}$, while using $\epsilon_{Q 2 D}=0.0021 \mathrm{~m}^{2} / \mathrm{s}$ the lifetime is $\sim 90 \mathrm{yr}$. These values are substantially larger than the envisioned lifetime of 15-20 yr (de Schipper et al., 2014; Stive et al., 2013).

The diffusion of the ZM produces a widening of the perturbation (Fig. 8), which implies feeding sand to adjacent beaches, measured here in terms of average linear meter gained at the beach:

$$
\overline{\Delta x}_{s}(t)=\frac{1}{y_{2}-y_{1}} \int_{y_{1}}^{y_{2}}\left(x_{s}(y, t)-x_{s}(y, 0)\right) d y
$$

92

The NE section ranged from $y_{1}=2100 \mathrm{~m}$ to $y_{2}=4600 \mathrm{~m}$ and the SW section from $y_{1}=7600 \mathrm{~m}$ to $y_{2}=10100 \mathrm{~m}$. The $2.5-\mathrm{km}$ long sections avoid the mainly diffusive area of the ZM tip and the influence area 


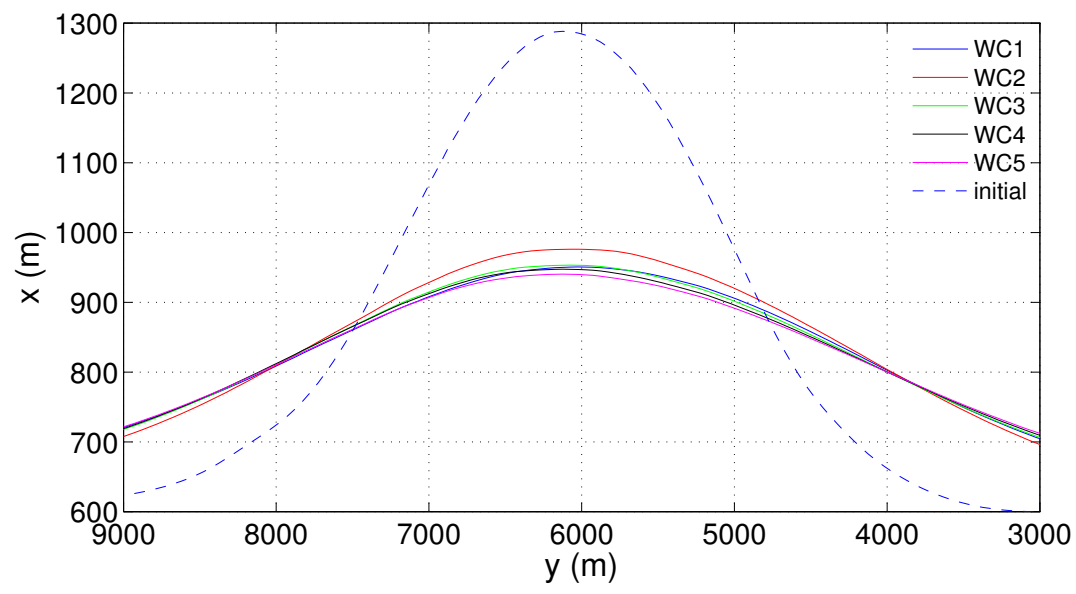

Figure 11: Shoreline modeled on March 2015 (dashed line) and shorelines predicted for the WC 30 yr after construction (solid lines).

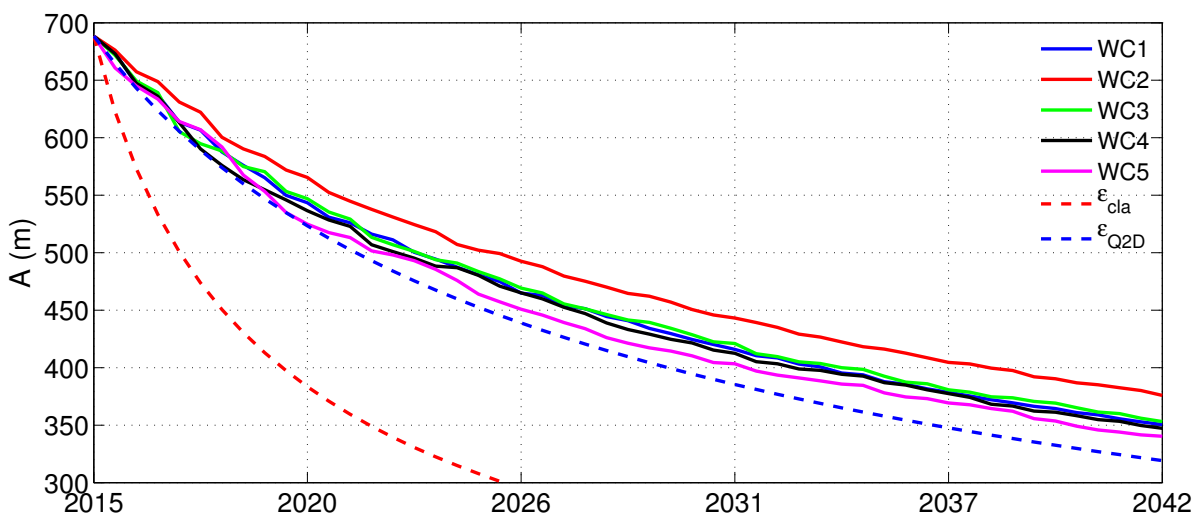

Figure 12: Modeled amplitude of the ZM during 27 yr, starting from March 2015.

of the harbors. Also, they are located at the same distance from the maximum amplitude position of the initial shoreline $(y=6100 \mathrm{~m}$ for 01 March 2015, as shown in Fig. 8). According to the model results, shown in Fig. 13, the NE section becomes wider than the SW section (about $100 \mathrm{~m}$ and $80 \mathrm{~m}$, respectively, after $27 \mathrm{yr}$ ). Both sections show notorious less feeding for the WC2 (coherent with the less diffusive behavior of that scenario). The feeding asymmetry, $F A$, is defined as the relative difference in $\overline{\Delta x}_{s}$ in $\mathrm{NE}$ and $\mathrm{SW}$ beaches and is evaluated as

$$
F A=2 \frac{\overline{\Delta x}_{s N E}-\overline{\Delta x}_{S S W}}{\overline{\Delta x}_{s N E}+\overline{\Delta x}_{s S W}}
$$

The one-line approach can not reproduce accurately the feeding magnitude nor the feeding asymmetry of the ZM (Fig. 13), using $\epsilon_{\text {cla }}$ the feeding is overpredicted by about $30 \%$ after $10 \mathrm{yr}$ and from then on it predicts retreat (also, see Fig. 14). By using $\epsilon_{Q 2 D}$, the one-line approach predicts much better the model results. Table 2 shows the averaged $F A$ over the last 5 yr of simulations, the WC2 produces the largest $F A$ while the remaining WC produce similar $F A$. The predictions of the shoreline sections using the WC3 for the Q2D-morfo model and the one-line approach are shown in Fig. 14.

The alongshore migration rate, $V$, of the shoreline perturbation was computed by finding the spatial lag for which the correlation between subsequent modeled shorelines, with a $20 \mathrm{~d}$ time step, is maximum. The 

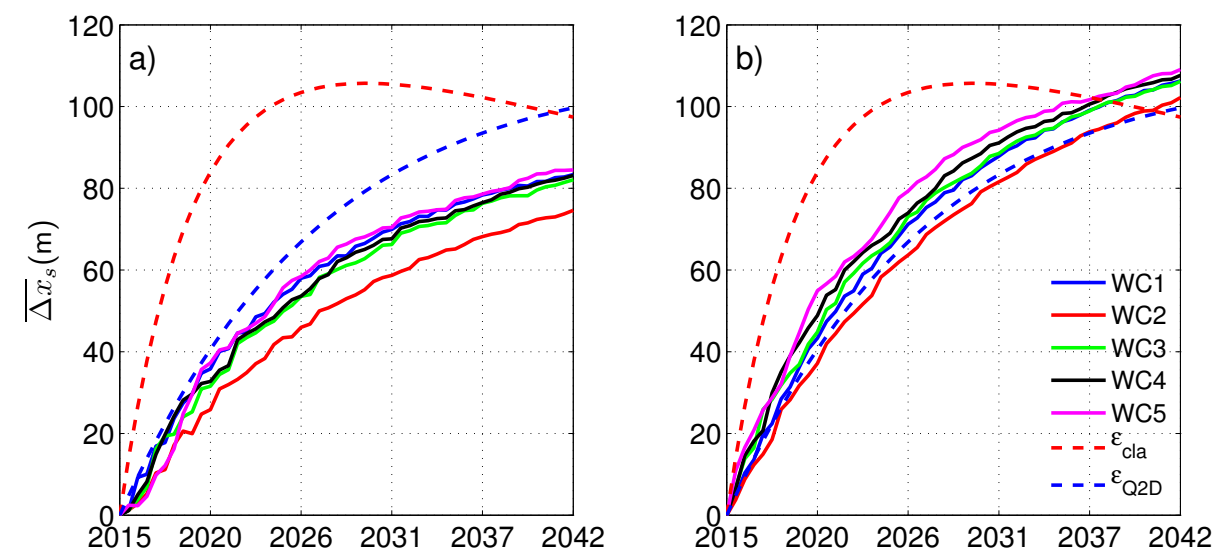

Figure 13: Beach linear meter gained in the defined sections along the coast (a) south-west and (b) north-east to the ZM during $27 \mathrm{yr}$, starting from March 2015.

Table 2: Morphologic parameters of the ZM behavior for the five WC, computed over the last five years of simulation.

\begin{tabular}{|l|l|l|l|l|}
$\mathrm{WC}$ & $\epsilon \mathrm{m}^{2} / \mathrm{s}$ & $V \mathrm{~m} / \mathrm{yr}$ & $F A$ & $S A$ \\
\hline 1 & 0.0016 & -4.3 & 0.24 & -0.016 \\
2 & 0.0013 & -3.4 & 0.31 & -0.010 \\
3 & 0.0016 & -2.2 & 0.26 & -0.007 \\
4 & 0.0017 & -1.8 & 0.26 & -0.006 \\
5 & 0.0018 & -1.1 & 0.25 & -0.003
\end{tabular}

obtained $V$ over the 27-yr period are small and north-east directed with a certain scatter for the different WC (Table 2), confirmed by the displacement of the crest position, $y_{c}$ (Fig. 15a). The wave power asymmetry, $P_{W} / P_{N}$, is the wave property that best correlates with the migration rate, i.e., the larger $P_{W} / P_{N}$ the larger $V$.

The shoreline shape asymmetry, $S A$, is here quantified as the relative difference between the beach areas (measured with $\overline{\Delta x}_{s}$ ) between the northern and southern sides of the tip with the same Eq. (26) of $F A$. However, to account for migration and widening of the perturbation we used dynamic integral limits $y_{1}=y_{c}-L_{g}, y_{2}=y_{c}$ for the northern side and $y_{1}=y_{c}, y_{2}=y_{c}+L_{g}$ for the southern side, where $y_{c}$ is the moving crest position and $L_{g}$ is the width of the evolving fitted Gaussian. $S A$ diminishes slightly for WC5, is rather stable for WC2, WC3 and WC4, and increases for WC1 (Fig. 15b). Table 2 shows the mean $S A$ over the last $5 \mathrm{yr}$ of evolution. A negative $S A$ denotes a larger shoreline slope in the NE than in the SW. The $S A$, just as $V$, correlates best with the wave power asymmetry.

\section{Discussion}

\subsection{Calibrated parameter values}

The model uses a series of parameters for the simulation of the alongshore and cross-shore transports. In particular the three empirical parameters are related to (i) the factor in the wave-driven alongshore transport (parameter $\mu$ ) (ii) the depth of closure $D_{c}$ (parameter $f_{c}$ ), and (iii) the diffusivity factor in $\vec{q}_{N}$ and $\overrightarrow{q_{D}}$ (parameter $\nu$ ). The nondimensional $K$ parameter in the CERC formula corresponding to the value for the $\mu$ parameter calibrated with the 400 initial days of ZM evolutionis $K=0.14$ (using $H_{r m s}$ in the CERC formula, Eq. 7). This value is unexpectedly small, somewhat smaller than the lower limit reported by Komar (1998). However, the value of $K$ is generally highly uncertain (see, e.g., Cooper and Pilkey, 2004) 

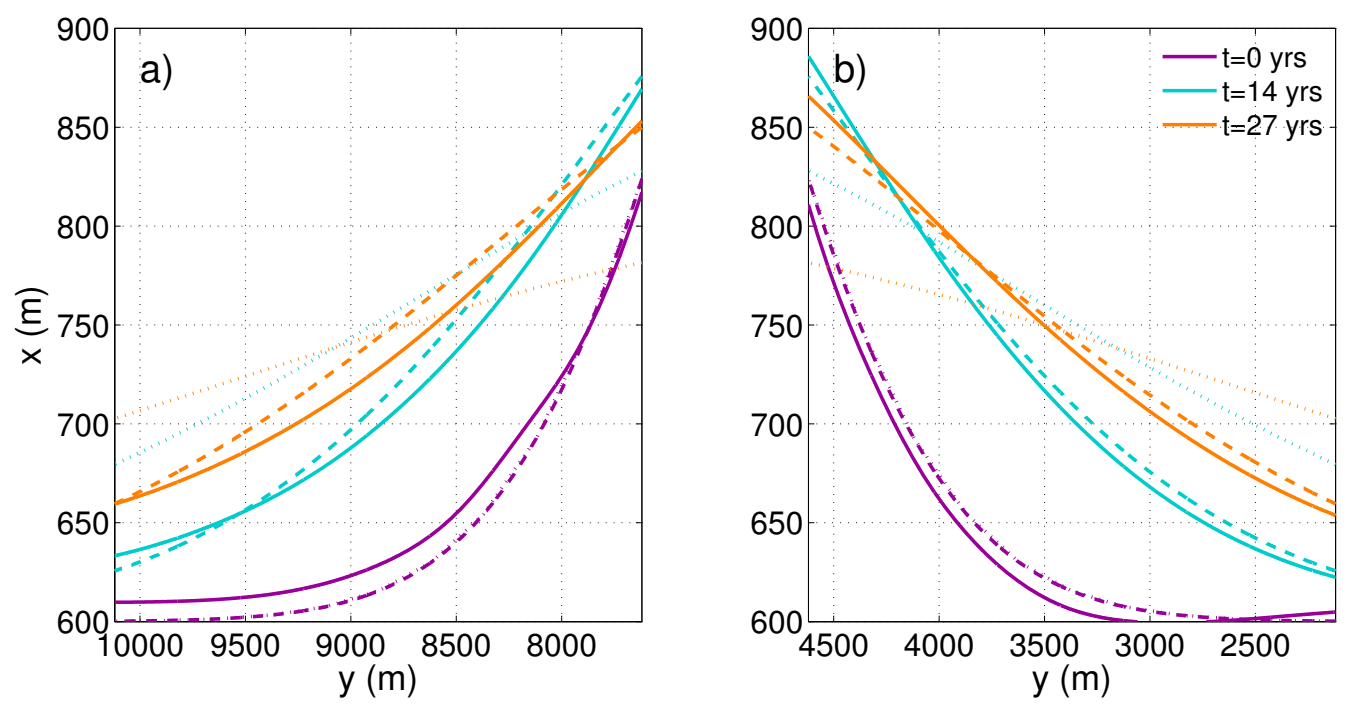

Figure 14: (a) Coastlines of the south-west section and (b) north-east section predicted by the Q2D-morfo model using WC3 (solid lines), and by using the one-line approach with $\epsilon_{Q 2 D}$ (dashed lines) and $\epsilon_{c l a}$ (dotted lines).

and for example, Wang et al. (1998) reported an even smaller value of $K=0.08$. Thus, our results provide a valuable opportunity of evaluating the effective $\mathrm{K}$ coefficient for such a large sand body.

We have also computed the annual alongshore sediment transport $\left(Q_{\text {annual }}\right)$ corresponding to the calibrated $\mu$ parameter in the CERC formula to asses the quantity of sand being transported and also to compare it to previous studies. The computation has been done by transforming the waves with the Q2Dmorfo model over an unperturbed bathymetry (i.e., rectilinear contours parallel to the coast, without the ZM) and assuming no morphological change for the waves from 1990 to 2014. The $Q_{\text {annual }}$ displays a high annual variability (Fig. 16). During the 24-yr period there is a net quantity of sand transported to the SW direction of 45,376 $\mathrm{m}^{3}$ (annual mean of about 1,900 $\mathrm{m}^{3}$ ), which is quite small compared with the largest $Q_{\text {annual }}$ obtained for 2010 (some 250,000 $\mathrm{m}^{3}$ ). Therefore, this indicates that there is no dominant sediment transport direction. This is in contrast with the results reported by van Rijn (1997), who analyzed the wave climate of the period 1980-1993 and found that the sediment transport was clearly directed towards the NE. In agreement with our findings, he found significant annual variability (e.g., using the wave climate of 1989 instead of that of 1994, the transport changed a factor 20). The discrepancy in transport direction between our study and that of van Rijn (1997) could be due to the differences in study period and wave station location. Wave-direction data is only available to us from the EURO-platform since April 1989, whilst van Rijn (1997) employed data form 1980-1993.

The depth of closure, $D_{c}$, is typically defined as the largest depth where bed level changes, during a certain time period (typically one year), are below a certain threshold of bottom change $U_{z b}$ (Hallermeier, 1978; Komar, 1998). Choosing $U_{z b}=0.1 \mathrm{~m}$, using the ZM bathymetric measurements, we find $D_{c}=9.2 \mathrm{~m}$, which agrees with the $D_{c}$ computed with the Hallermeier formula (using the $12 \mathrm{~h}$ exceeding wave height). The Q2D-morfo model uses an instantaneous $D_{c}$ value that is computed from the instantaneous wave conditions as a fraction, $f_{c}$, of the depth where sediment starts to be mobilized by waves. The calibration procedure finds $f_{c}=0.15$, so that the resulting $D_{c}$, averaged for the observed $12 \mathrm{~h}$ exceeding waves, is $9.5 \mathrm{~m}$. In contrast, Clinton and Nichols (1998) determined a $D_{c}=5 \mathrm{~m}$ for an area nearby the ZM, on the basis of a large bottom threshold, $U_{z b}=0.5 \mathrm{~m}$. This was motivated by the vertical accuracy of $0.25 \mathrm{~m}$ of the JarKus data. Using the same threshold on the ZM measurements a $D_{c}$ of $6.5 \mathrm{~m}$ is found. The $D_{c}$ values reported by de Schipper et al. (2016) for the ZM of 7-8 $\mathrm{m}$ are slightly smaller than our inferred $D_{c}$. Thus, despite that $D_{c}$ is usually understood as a statistical measure whereas our $D_{c}$ is an instantaneous value, our calibrated formulation and simulations agree quite well with the literature and the measurements. 

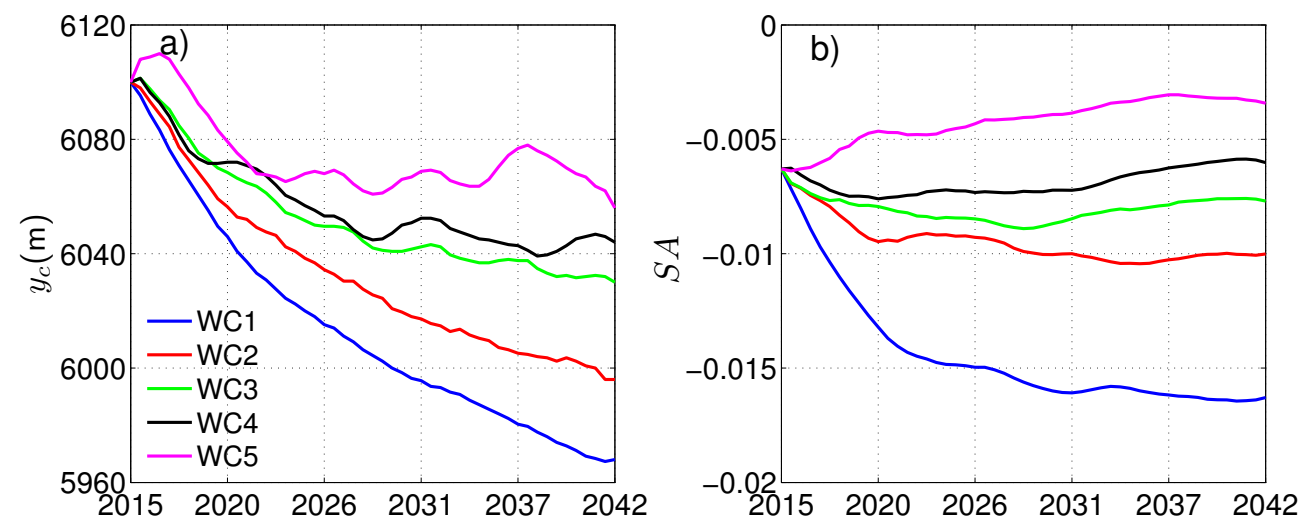

Figure 15: (a) Position of the ZM crest, $y_{c}$, and (b) the shoreline shape asymmetry, $S A$, during 27 yr, starting from March 2015.

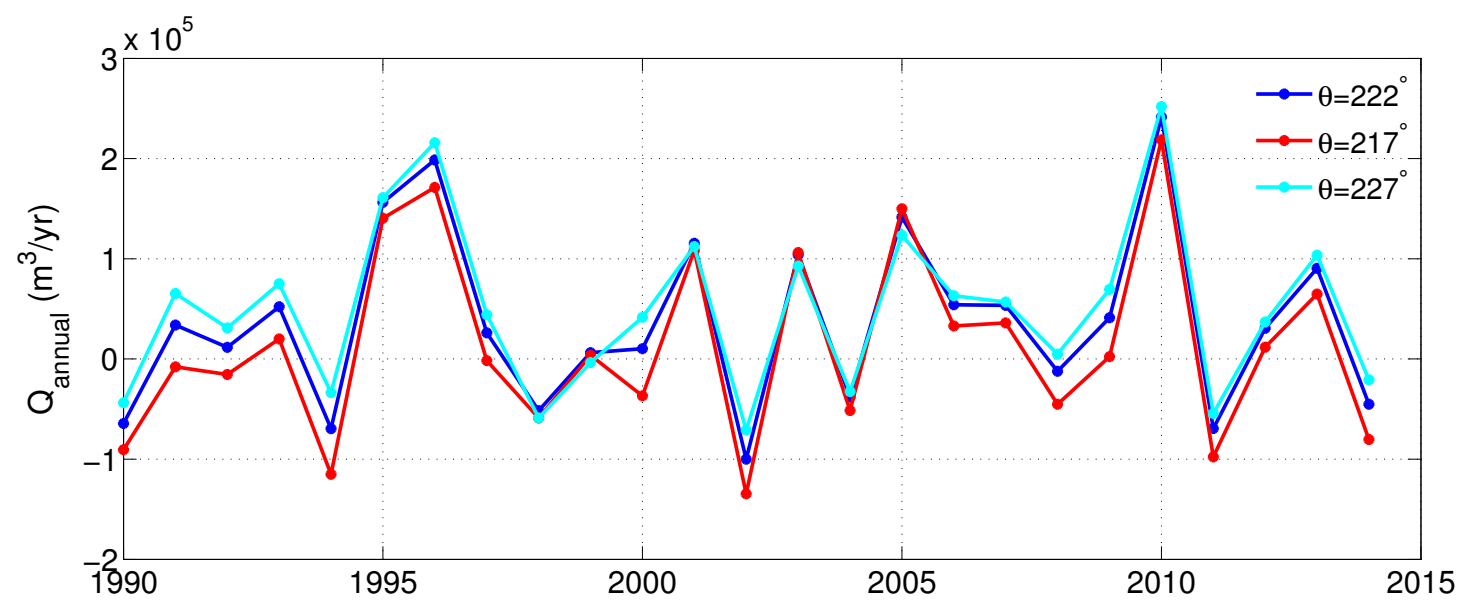

Figure 16: Net annual alongshore sediment transport computed with the Q2D-morfo model over an unperturbed bathymetry, where $Q>0$ means transport towards SW direction. The local shoreline orientation is of $222^{\circ}$ and the sensitivity of the transport to a variation in orientation of $\pm 5^{\circ}$ is also shown.

The Q2Dmorfo model could be a useful tool to test the design of mega-nourishments, in which case the different parameters of the model should be previously calibrated. As we have discussed in the previous paragraph, the Hallermeier formula can be used as a proxy for the depth of closure to then obtain a value for $f_{c}$. The two factors $\mu$ and $\nu$ in front of the transports should be calibrated for the specific site before applying the model. Also, if the beach of interest has similar geophysical properties as the ZM beach, the values for the parameters used in this contribution may be a good proxy. However, it is important to keep in mind that the Q2Dmorfo model does not include mechanisms that could play a role in the long-term behaviour of the ZM: surf-zone hydrodynamics, tides and aeolian sand transport.

\subsection{The role of HAWI in the ZM evolution}

Given that the wave climate on this stretch of coast has a large proportion of high-angle waves (i.e., offshore wave incidence angle larger than $45^{\circ}$ ) the $\mathrm{ZM}$ project provides a unique opportunity of checking high-angle wave instability (HAWI) theory. Ashton and Murray (2006) presented a one-line approach where the feedback of the bathymetric changes into the wave propagation is simplified, neglecting the curvature of the depth contours. They obtained a diffusion equation similar to Eq. (19) where the diffusivity $\epsilon$ can be 
negative for high-angle waves. We have computed the averaged diffusivity for the first three years with this approach and we have obtained $\epsilon=-0.0030 \mathrm{~m}^{2} / \mathrm{s}$, i.e., the coastline would become unstable so that selforganized shoreline sand waves might form. In contrast, both the measurements during the first three years and our model predictions for $30 \mathrm{yr}$ of the ZM, with $\epsilon=0.0014-0.0022 \mathrm{~m}^{2} / \mathrm{s}$, are diffusive. Apparently, the simplifications in the approach of Ashton and Murray (2006) overpredict the occurrence of HAWI. Indeed, in their approach only $50 \%$ of high-angle waves is required for a negative diffusivity whereas Q2D-morfo model requires a percentage of about $80 \%$ (van den Berg et al., 2012). Thus, the observed Dutch wave climate featuring only about $60 \%$ of high-angle waves could explain why the ZM is, in fact, diffusive. However, van den Berg et al. (2012) considered a constant offshore wave height. Here, using real time-varying wave conditions the percentage of oblique waves during storms might have more influence in the ZM behavior than the percentage of oblique waves in calm conditions. So, we have further analyzed the energetic waves ( $H>2 \mathrm{~m}$ ) in WC4, obtaining that $\sim 80 \%$ of the $\mathrm{W}$ high-energetic waves are above the threshold while only $\sim 30 \%$ of the $\mathrm{N}$ high-energetic waves are above it. Therefore, the ZM could show an anti-diffusive behavior during the $\mathrm{W}$ energetic events.

HAWI is induced by a positive feedback between the undulations in the depth contours and associated perturbations in wave refraction and shoaling while damped by the undulations in the coastline (see, e.g., Falqués et al., 2011a, for a description of the mechanisms). For relatively low wave incidence angles, the instability source is negligible, the stabilizing effect dominates and the shoreline perturbation diffuses with a diffusivity that is nearly independent on the angle. This is quite well reproduced by the classical one-line approach. In contrast, for relatively high wave angles the diffusivity depends on wave angle and eventually becomes negative above some threshold. Therefore, the significant influence of the wave angle on the diffusivity found with Q2D-morfo model suggests that the ZM is far from the purely diffusive situation described by the classical one-line approach and 'near' the HAWI threshold. For example, by jumping from $58 \%$ (WC5) to $62 \%$ (WC2) of high-angle waves the diffusivity drops by $16 \%$. Furthermore, the overprediction of the diffusivity by a 2.5 factor by the classical one-line approach is clearly a result of neglecting wave obliquity. Indeed, by forcing the real wave climate to have normal incidence (the period and wave height still vary) we find a diffusivity of $\epsilon=0.0053 \mathrm{~m}^{2} / \mathrm{s}$, which is near the classical theory with $\epsilon_{c l a}=0.0052 \mathrm{~m}^{2} / \mathrm{s}$, confirming the important role of wave incidence on the diffusivity. According to Falqués (2003) (see Fig. 5 of that paper), this 2.5 factor means that HAWI would be reached by increasing wave obliquity roughly by 18\%. Thus, as already suggested by Falqués (2006) (see also references therein), the Dutch coast is near the HAWI threshold.

Finally, a perfect diffusive behavior would show a constant $\epsilon$, while the diffusivity of the modeled shorelines drops from $0.0021 \mathrm{~m}^{2} / \mathrm{s}$, for the three-year validation period, to $0.0013-0.0018 \mathrm{~m}^{2} / \mathrm{s}$, for the $27-\mathrm{yr}$ long-term period. Initially, the ZM perturbation is pronounced at the shoreline but relatively weak at the depth contours, which results in a relatively strong diffusive behavior. However, through time, the mismatch between depth contours and shoreline tends to decrease, resulting in stronger de-stabilizing effects. If the diffusivity continues declining, a relict of the ZM may eventually survive . Therefore, feedback processes underlying HAWI are clearly active at the ZM even if stabilizing effects slightly dominate under the present wave climate.

\subsection{Feeding asymmetry}

The idea behind the ZM project is a mega-nourishment that feeds sand to adjacent beaches on a decadal time scale (de Schipper et al., 2016). Both the measurements of the first $3 \mathrm{yr}$ (Fig. 9) and the long-term simulations of $30 \mathrm{yr}$ (Fig. 13) indicate that there is an asymmetry between the feeding to the NE beaches and the SW beaches, the latter being smaller. de Schipper et al. (2016) already detected an asymmetry in the feeding by analyzing the first year of the ZM evolution, and suggested that this is a consequence of the dominant $\mathrm{NE}$ alongshore transport direction although in our analysis there is no indication of this dominance. Most important,the changes in shoreline position are governed by gradients in transport, not by the transport itself. Such transport gradients can be interpreted by the following three time-varying characteristics of the perturbation: diffusivity, $\epsilon$, migration, $V$, and the shoreline asymmetry, $S A$. The magnitude of the feeding is primarily controlled by $\epsilon$, which decreases the ZM amplitude and increases its width, whilst the feeding asymmetry, $F A$, may be related to $V$ and $S A$. Large northward V should produce 
larger feeding to the NE beaches, and hence a larger $F A$, but this effect is weakened if the perturbation has negative $S A$. Note also that the larger the wave power asymmetry, $P_{W} / P_{N}$, the larger $S A$ and $V$ ( Tables 1 and 2). Table 2 suggests that $V$ and $S A$ compensate each other, resulting in very similar $F A$ (for WC1, WC3, WC4, and WC5). Note that the arguments in this paragraph rely on an idealization, but in reality the transport gradients are more complex. For instance, a wave climate with a larger percentage of oblique waves, where HAWI processes become more important, adds complexity to the sediment transport, and this may explain the scatter of $F A$ for $\mathrm{WC} 2$. Therefore, a model, such as the Q2D-morfo, is required to predict such details in the long-term.

\section{Conclusions}

A morphodynamic model called Q2D-morfo has been successfully calibrated and validated with bathymetric measurements of a mega-nourishment constructed in July 2011 on the Dutch coast (Zandmotor, ZM), which is characterized by a bimodal wave climate with a significant percentage of high-angle waves. After being calibrated with the bathymetries measured during $1 \mathrm{yr}$, the model can properly reproduce the observed ZM evolution during the next 2 yr, not only the shoreline but also the depth contours so that sand volumes are well represented. The calibration of the model provides a value of the nondimensional $K$ parameter of the CERC formula of $K=0.14$, which is at the lowest limit of the values reported.

Long-term model simulations have been performed using five different wave climate scenarios, WC. Results show that the shoreline will behave diffusively, so that the amplitude of the perturbation will have decayed from the initial $960 \mathrm{~m}$ (immediately after construction) to about $350 \mathrm{~m}, 30 \mathrm{yr}$ after the ZM installation. At the same time, the shoreline of the adjacent beaches, $2.5 \mathrm{~km}$ at each side, will have shifted seaward (on average) by about $100 \mathrm{~m}$ at the NE defined section and about $80 \mathrm{~m}$ at the SW defined section. These results are very robust since they are reproduced with the five applied WC. The model predicts small alongshore migration rates (due to the bidirectional WC) and a maintenance of the shape asymmetry, $S A$, both correlate with the wave power asymmetry. The diffusivity is smallest for the WC showing the largest percentage of high-angle waves.

An effective diffusivity of the shoreline, due to the alongshore sediment transport, has been evaluated by analyzing the shoreline evolution during the first $3 \mathrm{yr}$, obtaining similar results for the measured and the modeled shorelines, $\epsilon_{o b s}=0.0022 \mathrm{~m}^{2} / \mathrm{s}$ and $\epsilon_{Q 2 D}=0.0021 \mathrm{~m}^{2} / \mathrm{s}$, respectively. In contrast, the classical one-line approach overpredicts the diffusion by a factor of $2.5, \epsilon_{\text {cla }}=0.0052 \mathrm{~m}^{2} / \mathrm{s}$. Therefore, the ZM lifetime, here defined as the time needed to reduce the amplitude after construction by a factor 5 , predicted by $\epsilon_{c l a}$ is of only $\sim 35 \mathrm{yr}$ instead of the $\sim 90 \mathrm{yr}$ computed with the $\epsilon_{Q 2 D}$. It is found that the alongshoredriven effective diffusivity must be evaluated at least $1 \mathrm{yr}$ after the mega-nourishment construction to avoid the strong influence of cross-shore transport at the initial states when the perturbed profiles are far from equilibrium. Although the measurements over the first three years and the model predictions for $30 \mathrm{yr}$ show a diffusive behavior of the ZM, the significant reduction in coastline diffusivity compared with the classical one-line approach, attributable to wave obliquity, confirms that the Dutch coast is not far from high-angle wave instability.

A morphodynamic model like the Q2D-morfo, which includes more physical processes than the oneline approach but still allows performing long-term simulations, is especially suited to predict the shoreline evolution of mega-nourishments. In particular, the model can be a useful tool for the design of meganourishments since it can accurately reproduce the diffusion, the alongshore migration, and the feeding asymmetry to adjacent beaches.

\section{Acknowledgements}

This research is part of the projects CTM2012-35398 and CTM2015-66225-C2-1 funded by the Spanish Government and cofunded by the E.U. (FEDER). The first author is funded by the Mexican Government (CONACyT, grant number 217754). The authors warmly thank Prof. Dr. M.J.F. Stive for encouraging the fruitful cooperation between the UPC and UU groups that has led to the present research work. Jantien Rutten and Gerben Ruessink were supported by the Dutch Technology Foundation STW that is part of the 
Dutch Organization for Scientific Research (NWO), and which is partly funded by the Ministry of Economic Affairs, under contract 12686 (Nature Coast: S1 Coastal Safety).

\section{References}

\section{References}

Ashton, A., Murray, A. B., 2006. High-angle wave instability and emergent shoreline shapes: 2. Wave climate analysis and comparisons to nature. J.Geophys.Res. 111, F04012,doi:10.1029/2005JF000423.

Ashton, A., Murray, A. B., Arnault, O., 2001. Formation of coastline features by large-scale instabilities induced by high-angle waves. Nature 414, 296-300.

Bender, C. J., Dean, R. G., 2003. Wave field modification by bathimetric anomalies and resulting shoreline changes: a review with recent results. Coastal Eng. 49, 125-153.

Cooper, J., Pilkey, O., 2004. Longshore drift: Trapped in an expected universe. J. Sediment. Res. 74, 599-606.

de Ruig, J. H. M., Hillen, R., 1997. Developments in Dutch coastline management: Conclusions from the second governmental coastal report. J. Coastal Conservation 3, 203-210.

de Schipper, M. A., de Vries, S., Ruessink, G., de Zeeuw, R. C., Rutten, J., van Gelder-Mass, C., Stive, M. J. F., 2016. Initial spreading of a mega feeder nourishment: Observations of the Sand Engine pilot project. Coastal Eng. (111), 23-38.

de Schipper, M. A., de Vries, S., Rutten, J., Aarninkhof, S., 2014. Morphological development of a mega-nourishment; first observations of the Sand Engine. In: Coastal Eng. 2014. Doi: 10.9753/icce.v34.sediment.73.

Falqués, A., 2003. On the diffusivity in coastline dynamics. Geophys. Res. Lett. 30 (21), 2119, doi:10.1029/2003GL017760.

Falqués, A., 2006. Wave driven alongshore sediment transport and stability of the Dutch coastline. Coastal Eng. 53, $243-254$.

Falqués, A., Calvete, D., 2005. Large scale dynamics of sandy coastlines. Diffusivity and instability. J. Geophys. Res. 110 (C03007), doi:10.1029/2004JC002587.

Falqués, A., Calvete, D., Ribas, F., 2011a. Shoreline instability due to very oblique wave incidence: Some remarks on the physics. J. Coastal Res. 27 (2), 291-295.

Falqués, A., van den Berg, N., Ribas, F., Caballeria, M., 2011b. Modelling shoreline sand waves. Application to the coast of Namibia. In: River, Coastal and Estuarine Morphodynamics: RCEM 2011. Cd-rom.

Hallermeier, R. J., 1978. Uses for a calculated limit depth to beach erosion. In: Coastal Eng. 1978. Am. Soc. of Civ. Eng., pp. 1493-1512.

Hamm, L., Capobianco, M., Dette, H. H., Lechuga, A., Spanhoff, R., Stive, M. J. F., 2002. A summary of European experience with shore nourishment. Coastal Eng. 47, 237-264.

Kaergaard, K., Fredsoe, J., Knudsen, S. B., 2012. Coastline undulations on the West Coast of Denmark: Offshore extent, relation to breaker bars and transported sediment volume. Coastal Eng. 60, 109-122.

Komar, P. D., 1998. Beach Processes and Sedimentation, 2nd Edition. Prentice Hall, Englewood Cliffs, N.J.

Pelnard-Considère, R., 1956. Essai de theorie de l'evolution des formes de rivage en plages de sable et de galets. In: 4th Journees de l'Hydraulique, Les Energies de la Mer, Paris. Vol. III(1). Société Hydrotechnique de France, pp. $289-298$.

Ruessink, B. G., Jeuken, M. C. J. L., 2002. Dunefoot dynamics along the Dutch coast. Earth Surf. Process. Landforms 27, $1043-1056$

Stive, M. J. F., de Schipper, M. A., Luijendijk, A. P., Aarninkhof, S. G. J., van Gelder-Maas, C., van Thiel de Vries, J. S. M., de Vries, S., Henriquez, M., Marx, S., Ranasinghe, R., 2013. A new alternative to saving our beaches from sea-level rise: The sand engine. Coastal Eng. 29 (5), 1001-1008.

van den Berg, N., Falqués, A., Ribas, F., 2011. Long-term evolution of nourished beaches under high angle wave conditions. J. Marine Systems 88, 102-112.

van den Berg, N., Falqués, A., Ribas, F., 2012. Modelling large scale shoreline sand waves under oblique wave incidence. J. Geophys. Res. 117 (F03019), doi:10.1029/2011JF002177.

van den Berg, N., Falqués, A., Ribas, F., Caballeria, M., 2014. On the wavelength of self-organized shoreline sand waves. J. Geophys. Res. Earth Surf. 119, 665-681, doi:10.1002/2013JF002751.

van Rijn, L. C., 1997. Sediment transport and budget of the central coastal zone of Holland. Coastal Eng. 32, 61-90.

Wang, P., Krauss, N. C., Davis, R. A., 1998. Total longshore sediment transport rate in the surf zone: field measurements and empirical predictions. Coastal Res. 14, 268-298.

Wijnberg, K. M., Kroon, A., 2002. Barred beaches. Geomorphology 48, 103-120.

Wijnberg, K. M., Terwindt, J. H. J., 1995. Extracting decadal morphological behavior from high-resolution, long-term bathymetric surveys along the Holland coast using eigenfunction analysis. Mar. Geol. 126, 301-330.

Yu, J., Slinn, D. N., 2003. Effects of wave-current interaction on rip currents. J. Geophys. Res. 108 (C33088), doi:10.1029/2001JC001105. 